\title{
JEFFERSON
}

\section{Containment Data Report}

\author{
Ted Stubbs \\ Billy Hudson \\ Ray Heinle
}

\section{December 1994}

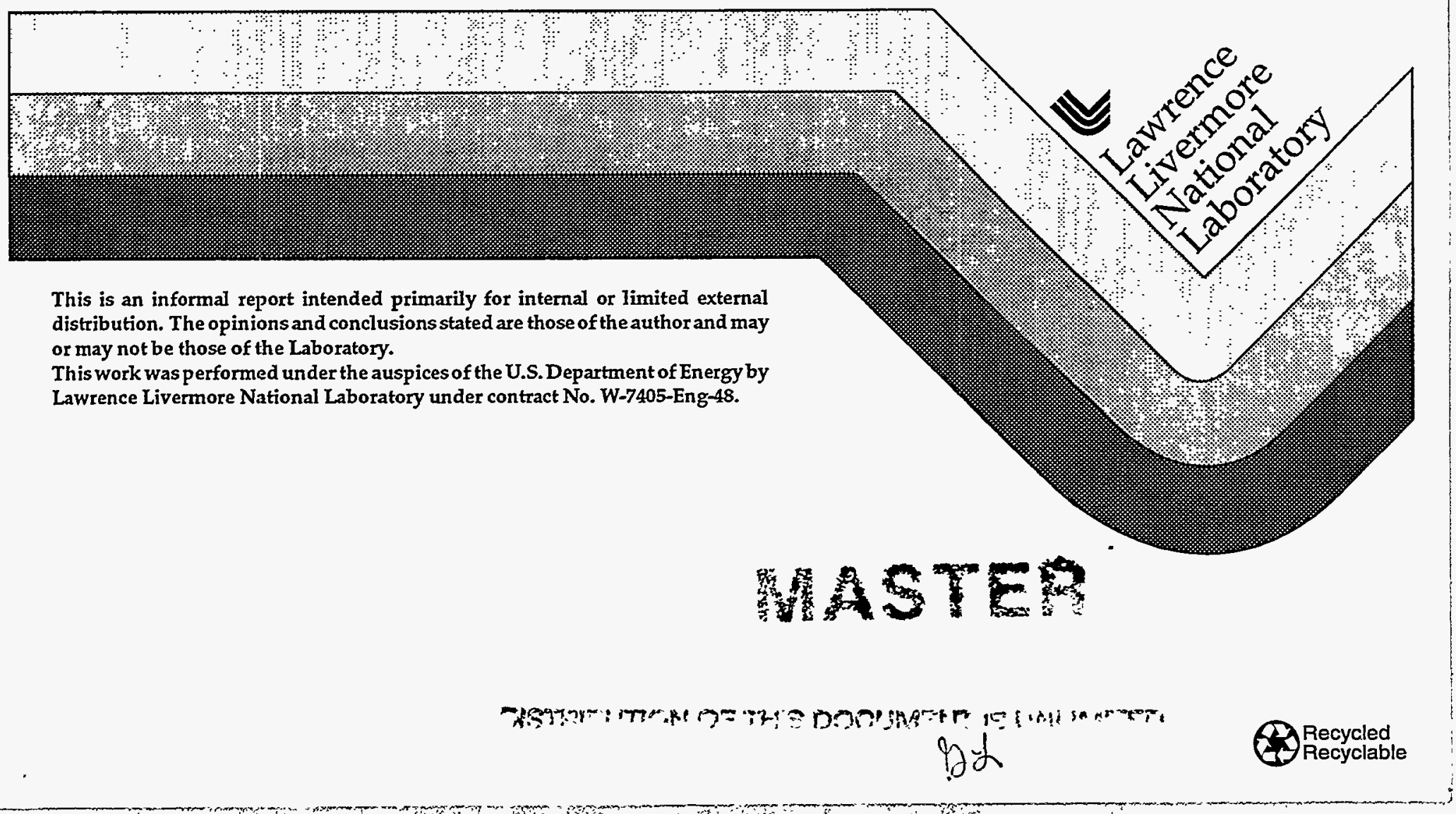




\section{DISCLAIMER}

This document was prepared as an account of work sponsored by an agency of the United States Government. Neither the United States Government nor the University of California nor any of their employees, makes any warranty, express or implied, or assumes any legal liability or responsibility for the accuracy, completeness, or usefulness of any information, apparatus, product, or process disclosed, or represents that its use would not infringe privately owned rights. Reference herein to any specific commercial product, process, or service by trade name, trademark, manufacturer, or otherwise, does not necessarily constitute or imply its endorsement, recommendation, or favoring by the United States Government or the University of California. The views and opinions of authors expressed herein do not necessarily state or reflect those of the United States Government or the University of California, and shall not be used for advertising or product endorsement purposes.

This report has been reproduced directly from the best available copy.

Available to DOE and DOE contractors from the Office of Scientific and Technical Information P.O. Box 62, Oak Ridge, TN 37831

Prices available from (615) 576-8401, FTS 626-8401

Available to the public from the National Technical Information Service

U.S. Department of Commerce 5285 Port Royal Rd. Springfield, VA 22161 


\section{DISCLAIMER}

Portions of this document may be illegible in electronic image products. Images are produced from the best available original document. 


\begin{tabular}{lll} 
Classification Guide & TopicNumber & \multicolumn{1}{c}{ Subiect } \\
COK-88-024 & 1.5 .6 & Event announcement \\
NV-89-18 & & Event announcement \\
TCG-WT-1 & 1113 & Contractor identification \\
TCG-WT-1 & 1121 & Personnel identification \\
TCG-WT-1 & 1210 & Geology \\
TVG-WT-1 & 1260 & Crater (map) \\
TCG-WT-1 & 1413 & Statement concerning venting \\
TCG-WT-1 & 1452 & Event announcement \\
TCG-WT-1 & 1831 & Depth of burial \\
TCG-WT-1 & 1843 & Stemming material, amount,etc \\
TCG-WT-1 & 1925 & Diagnostic canister dimensions \\
TCG-WT-1 & 3542.3 & Ground motion \\
TCG-WT-1 & 4810 & Radiation measurement \\
TCG-WT-1 & 4820 & Acceleration, pressure, \\
& & temperature measurement
\end{tabular}


JEFFERSON instrumentation Summary

\begin{tabular}{|c|c|c|c|}
\hline Instrumentation & Fielded & $\begin{array}{c}\text { Data } \\
\text { Return }\end{array}$ & $\begin{array}{l}\text { Present in } \\
\text { this Report }\end{array}$ \\
\hline Plug Emplacement & yes & yes & yes \\
\hline Radiation & yes & yes & yes \\
\hline \multicolumn{4}{|l|}{ Pressure } \\
\hline Stemming & yes & yes & yes \\
\hline Challenge & no & - & - \\
\hline Cavity & no & - & - \\
\hline Atmospheric & no & - & - \\
\hline \multicolumn{4}{|l|}{ Motion } \\
\hline Free field & no & - & - \\
\hline Surface & yes & yes & yes \\
\hline Plug & no & - & - \\
\hline Stemming & yes & yes & yes \\
\hline Surface casing & no & - & - \\
\hline Emplacement pipe & no & - & - \\
\hline Recording trailer & yes & yes & yes \\
\hline Hydroyield (a) & yes & yes & no \\
\hline Collapse (b) & yes & yes & yes \\
\hline Stress $(c)$ & yes & yes & yes \\
\hline Strain (d) & yes & yes & yes \\
\hline Qther Measurements & yes & yes & yes \\
\hline
\end{tabular}

(a) CORRTEX in emplacement hole.

(b) EXCOR and CLIPER in emplacement hole.

(c) In bottom plug.

(d) In top plug.

Event Personnel

Containment Physics

B. Hudson

J. Kalinowski

T. Stubbs
LLNL

EG\&G/AVO

EG\&G/AVO
Instrumentation
C. Cordill
LLNL
R. Salazar
EG\&G/AVO
R. Spilsbury
A. Moeller
EG\&G/NVO
EG\&G/NVO 


\section{Contents}

1. Event Description

1.1 Containment summary

1.2 Site .

1.3 Instrumentation .

2. Emplacement

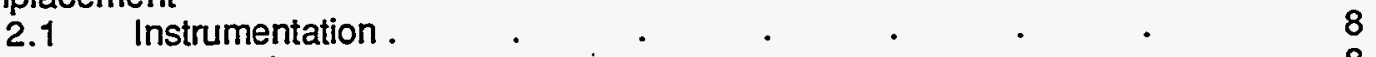

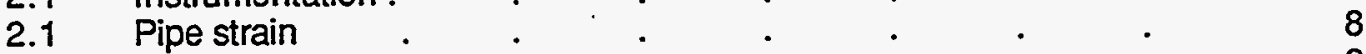

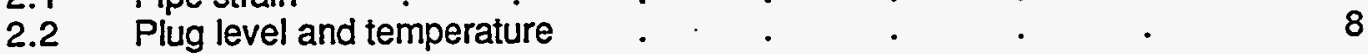

3. Stemming Performance

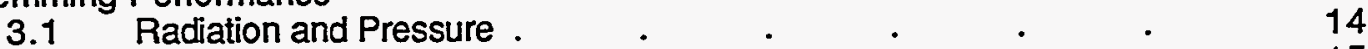

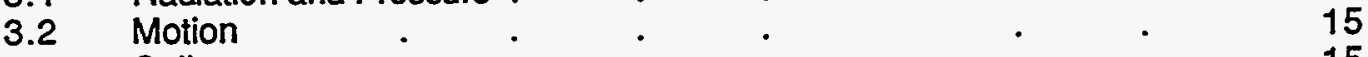

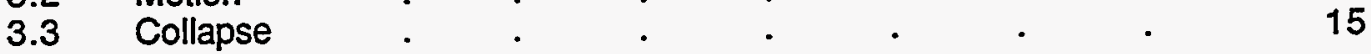

4. Other Measurements

4.1 Motion at the LLNL trailer park . . . . . . . $\quad 39$

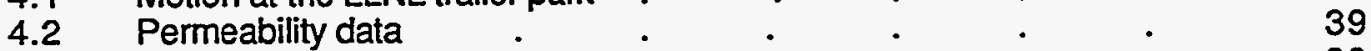

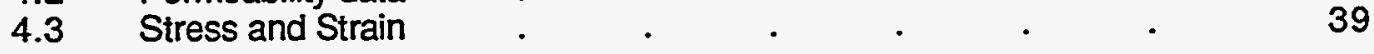

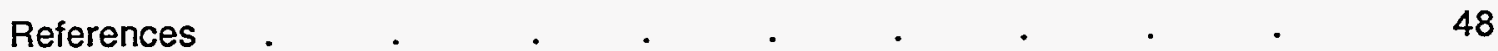




\section{Event Description}

\subsection{Containment summary}

The JEFFERSON event was detonated in hole U20ai of the Nevada Test Site (see figure 1.1). Detonation time was 06:30 PDT on April 22, 1986. A subsurface collapse extending upward to a depth of about $190 \mathrm{~m}$ (just above plug four, the stemming platform) occurred about 2 hours 38 minutes after detonation. No radiation arrivals were detected above ground and the JEFFERSON event containment was considered satisfactory.

\subsection{Site}

A magnified geologic map showing some of the surface features near the U20ai site is shown in Figure 1.2. The device had a burial depth of $608 \mathrm{~m}$ in Area 4 tuffs, about $20 \mathrm{~m}$ above the static water level (SWL), as shown in the geologic cross sections (figure 1.3(1)).

Stemming of the $2.44 \mathrm{~m}$ diameter emplacement hole followed the plan shown in figure 1.4. A log of the stemming operations was maintained by Holmes \& Narver(2).

\subsection{Instrumentation}

Figure 1.5 gives a schematic layout of the instrumentation in hole U20ai, designed to monitor the stemming emplacement procedures and performance on the JEFFERSON event.

Each of the five sanded gypsum concrete (SGC) plugs was monitored during emplacement with arrays of thermistors and conductivity probes to determine its position, thickness and curing history. Pressure and radiation were monitored in the coarse stemming on either side of the central three SGC plugs. All data signals from these stations were transmitted in analog form to the recording trailer where they were recorded on magnetic tape.

Sensitive pressure transducers were fielded below plugs $4 \& 5$ and in the ground surface as part of an investigation of the permeability of the upper layers of the Nevada Test Site. Signals from these stations were digitized through a Waveteck ${ }^{\circledR}$ system and recorded on disk by a LSI 11/23 computer. 
Hydrodynamic yield of the device and cavity collapse and chimney formation were monitored by two CLIPER/CORRTEX cables and one EXCOR/CORRTEX cable. Results of the hydrodynamic yield measurements are reported elsewhere $(3)$.

$\mathrm{Bl}$-axial stress and strain transducers ${ }^{(4)}$ were fielded in the bottom plug as part of a continuing transducer development program to measure stress near the $1.0 \mathrm{Kbar}$ level.

Vertical motion was monitored in each of the five SGC plugs, in the stemming between the plugs, on the surface casing and in the ground surface, $15.24 \mathrm{~m}$ from surface ground zero (SGZ). Triaxial motion of the recording trailer was also recorded. Relative displacement between the surface casing and the top plug was monitored by an array of seven proximity switches mounted in the plug next to the bottom of the surface casing.

A brief history of the fielding operations of the instrumentation, including emplacement pipe strain measurements, is given in reference 5 . Further details of the instrumentation are given in reference 6. 


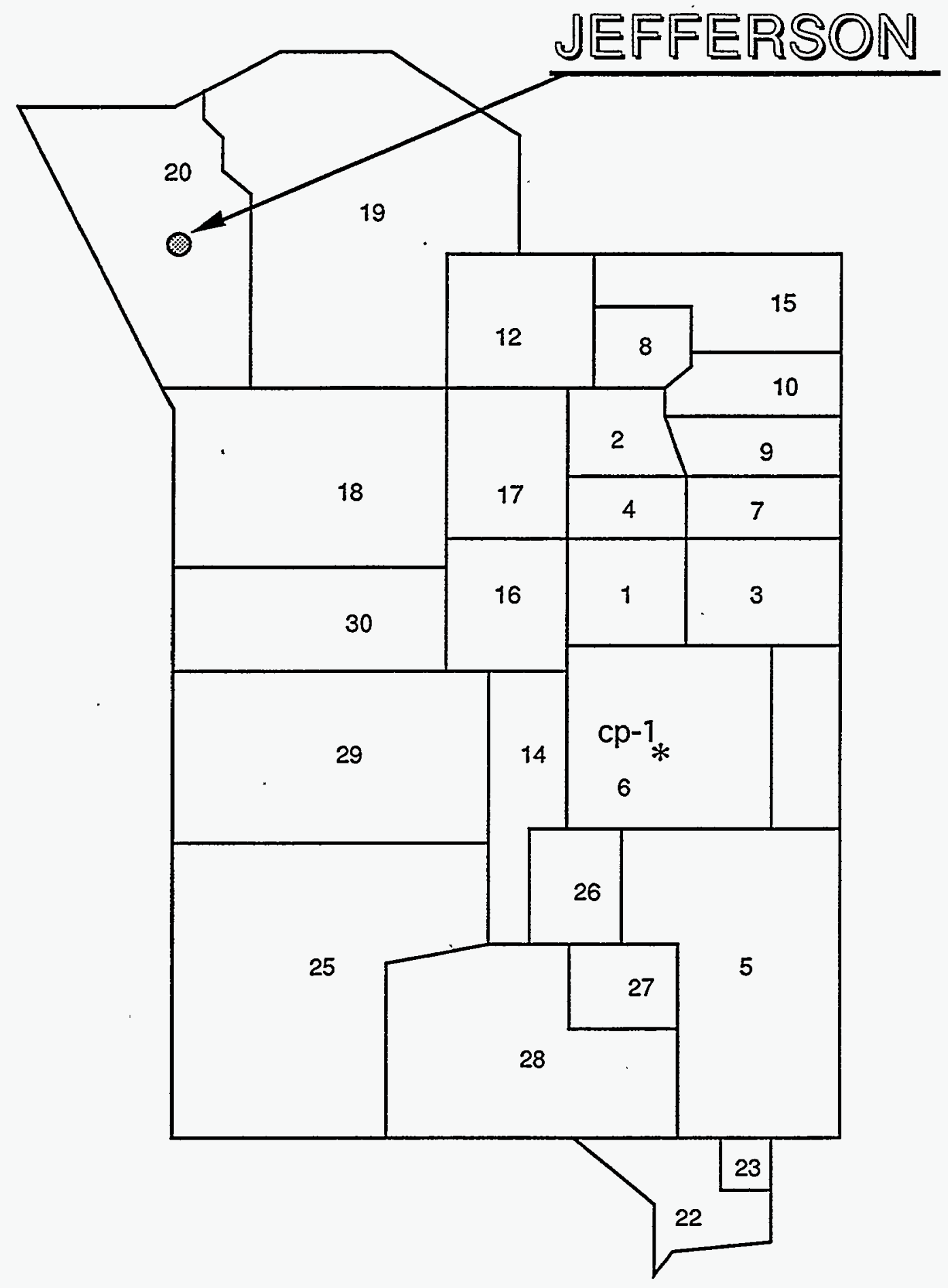

Figure 1.1 Map of the Nevada Test Site indicating the location of hole U20ai. 


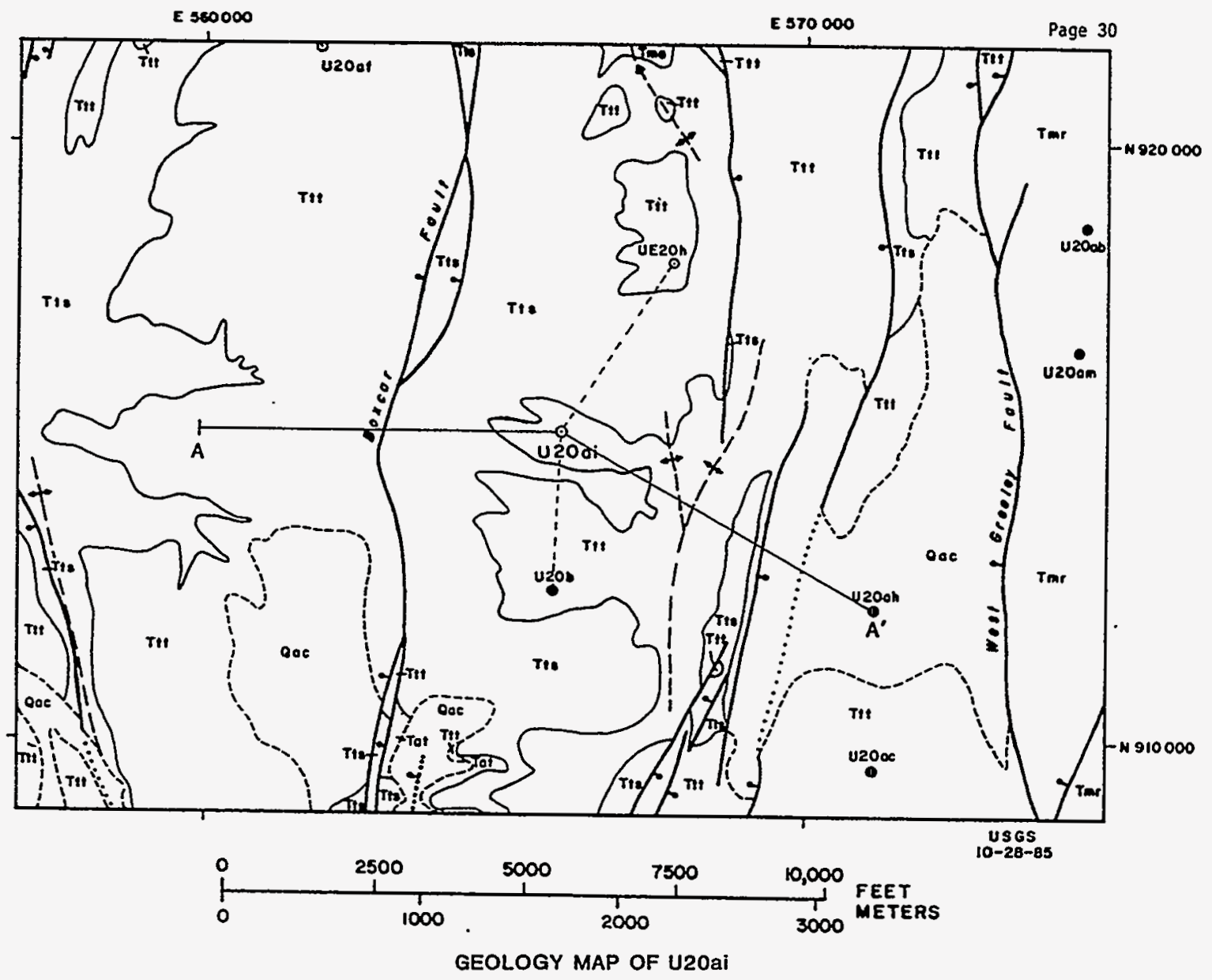

Figure 1.2 Geologic Map of the region near hole U20ai. 


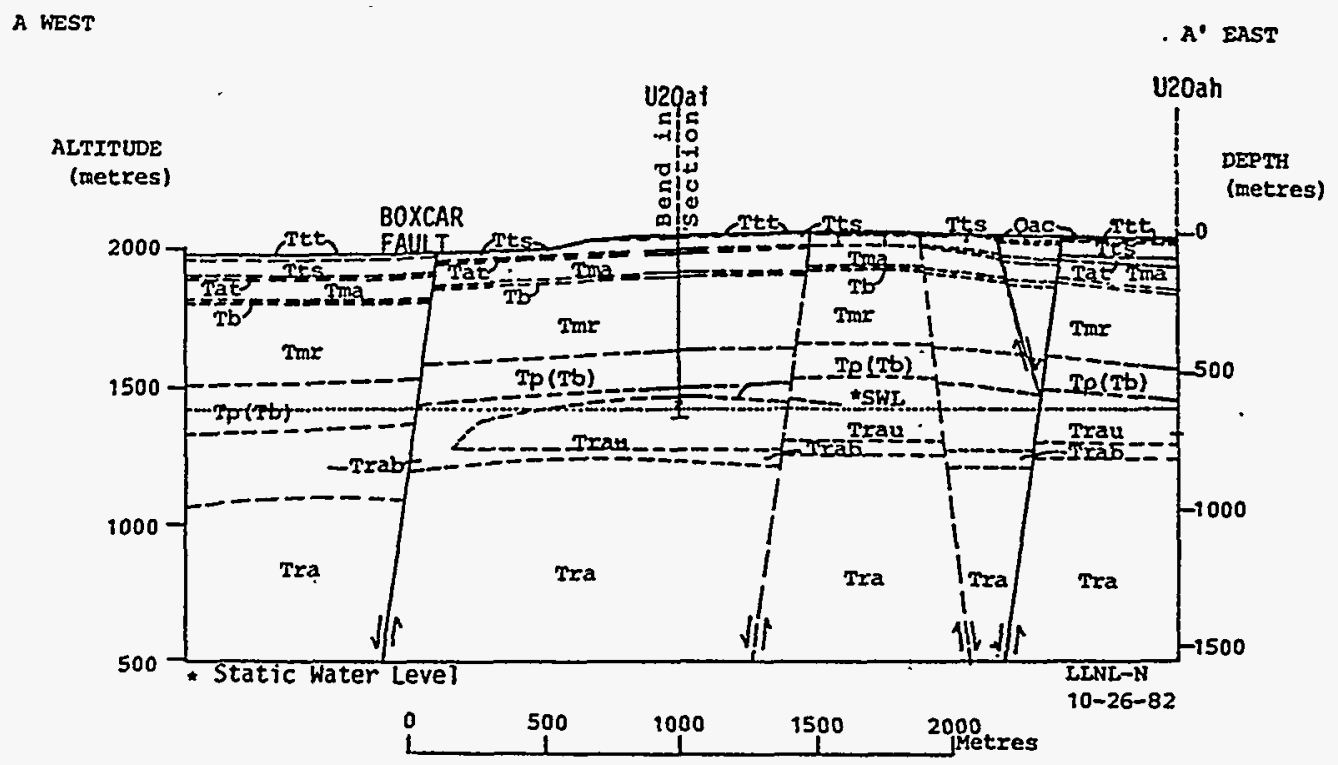

GEOLOGIC CROSS SECTION THROUGH U2OAi

Identification of units used in the geologic map and cross section, U20ai

Quaternary units

Qac

Alluvium and colluvium

Tertiary units

Ttt

Trail Ridge Member, Thirsty Canyon Tuff

Spearhead and Rocket Wash (?) Members, Thirsty Canyon Tuff

Ash-fall and reworked tuff

Ammonia Tanks Member, Timber Mountain Tuff

Vitric Bedded Tuff

Rainier Mesa Member, Timber Mountain Tuff

Bedded tuff associated with the Paintbrush Tuff

Bedded and ash-flow tuffs, tuffs and rhyolites of Area 20

Upper rhyolite lavas, tuffs and rhyolites of Area 20

Tuffs and rhyolites of Area 20, undifferentiated

Figure 1.3 Geologic cross section through hole U20ai. 


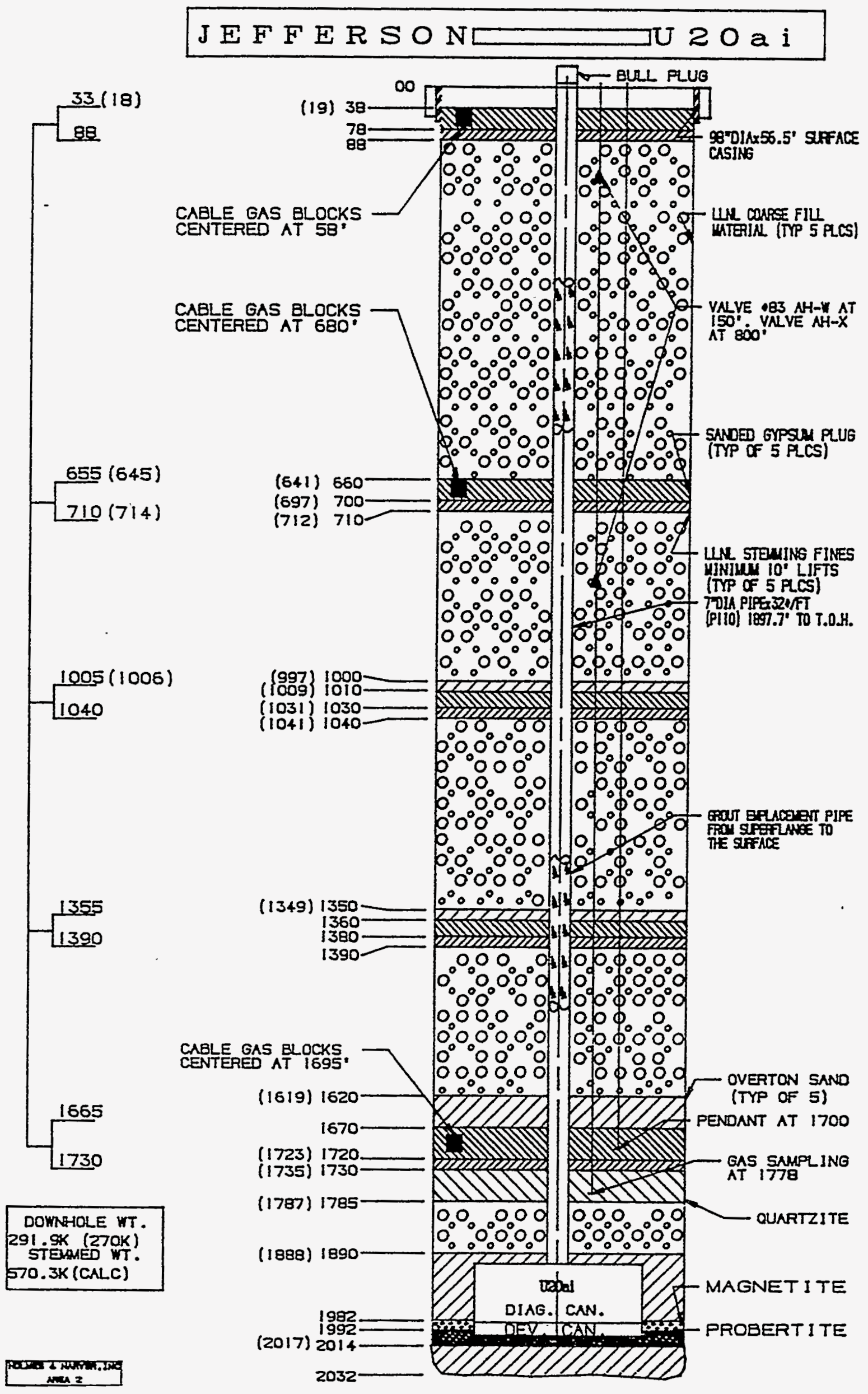

Figure 1.4 As-built stemming plan for hole U20ai. 


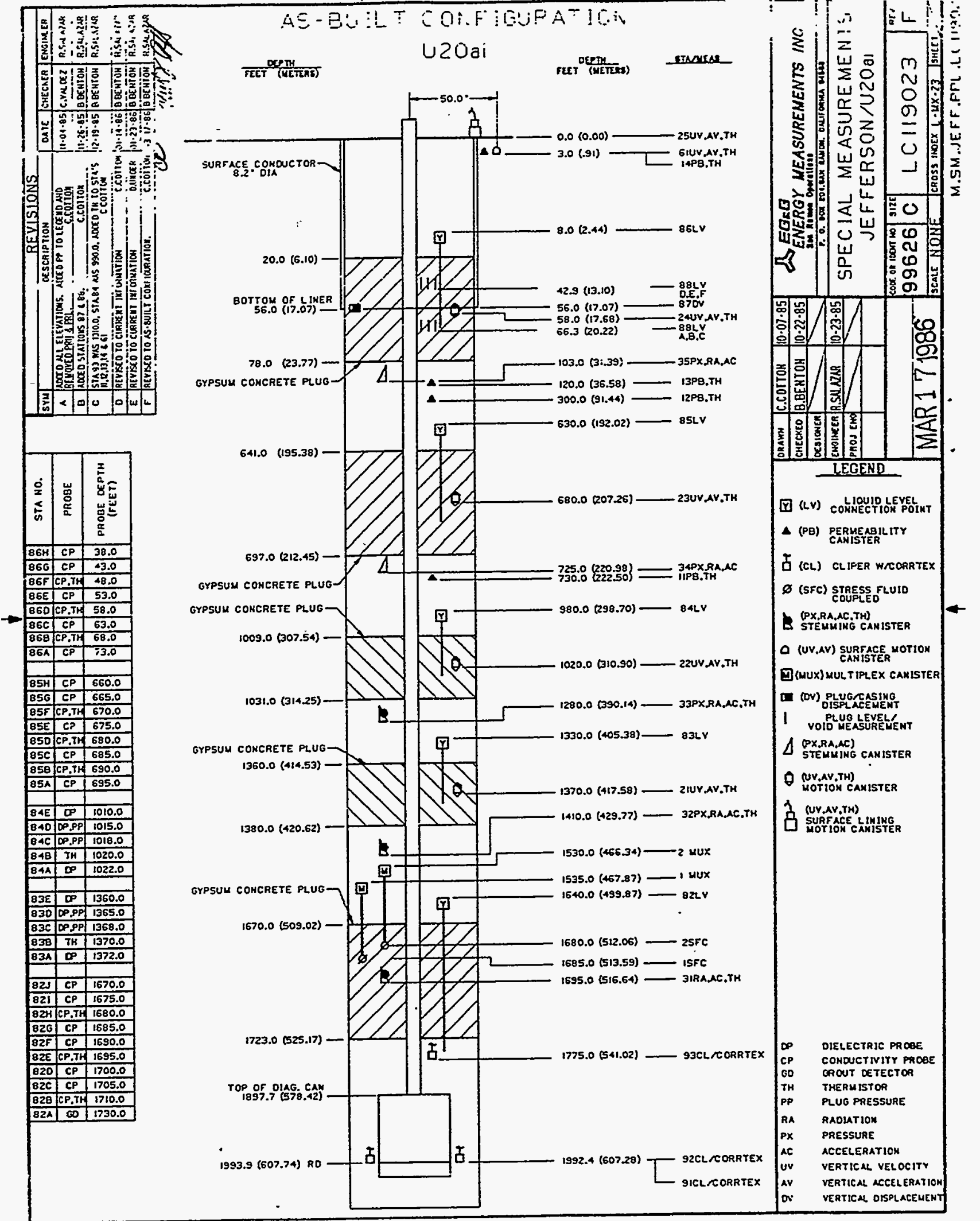

Figure 1.5 As-built containment instrumentation plan for the JEFFERSON event emplacement hole U20ai. 


\section{Emplacement}

\subsection{Instrumentation}

During installation, some of the mounting brackets were broken on the motion canisters intended to be placed in plugs one, three and four. This allowed the orientation of the canisters to be slightly off vertical.

\subsection{Pipe strain}

Strain on the emplacement pipe was not recorded on JEFFERSON.

\subsection{Plug levels and temperature}

The emplacement of each of the five SGC plugs was monitored with an array of conductivity probes and thermistors. The locations of the probes are tabulated in figure 1.5. Figures 2.1-2.5 show plots of the SGC emplacement and temperature histories. Open circles indicate the upper and lower boundary positions of the plugs as measured using tag lines while solid circles indicate the positions of the probe stations and the times at which the conductivity probes were activated. Most of the temperature sensors accompanied conductivity probes as indicated in figure 1.5 and the captions of figures 2.1-2.5. The temperature probes in the second and third plugs were fielded midway between conductivity sensors.

All plugs were emplaced as planned. 


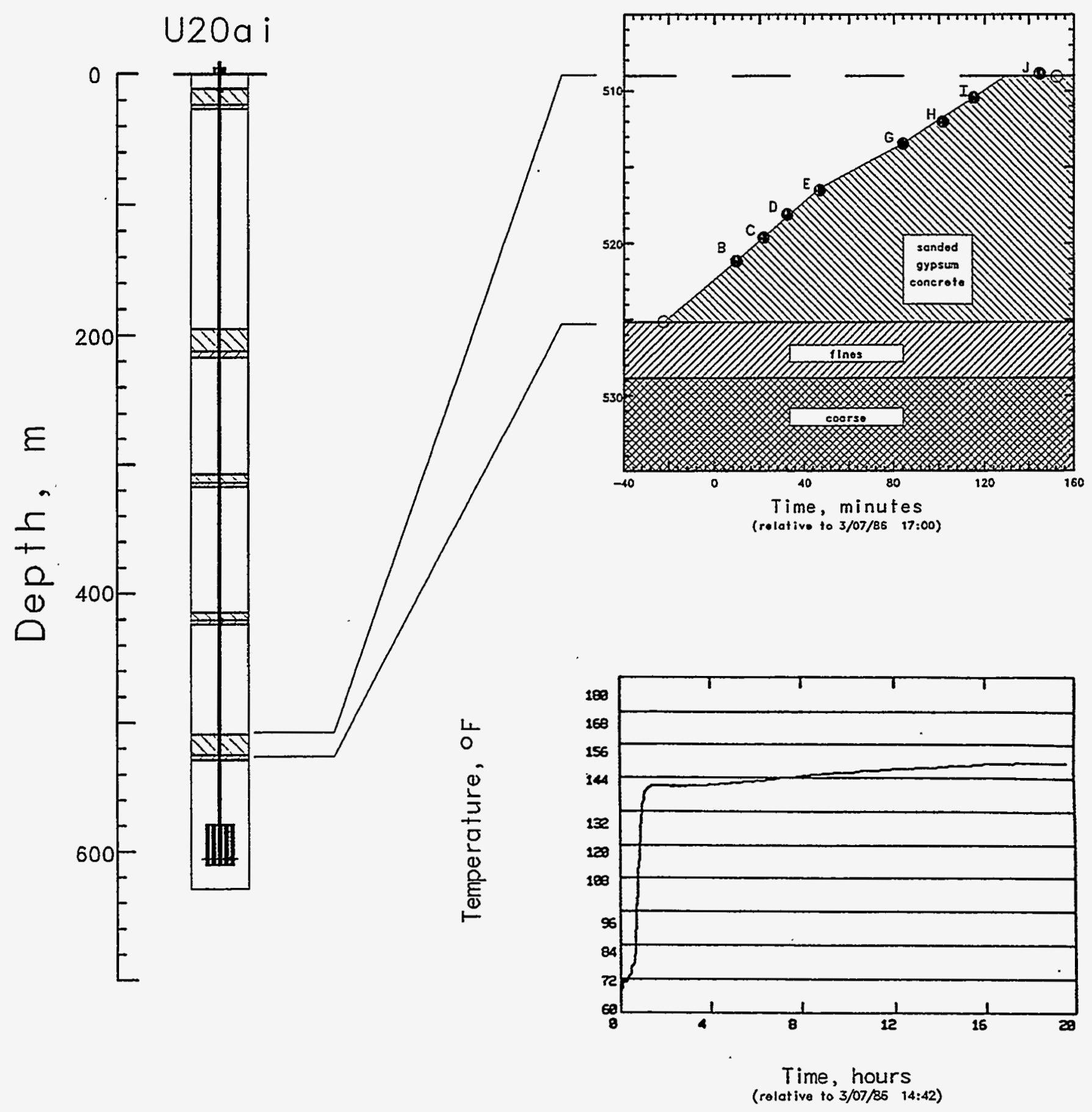

Figure 2.1 Sanded gypsum emplacement for the first plug. The upper and lower plug boundaries were determined with a tag line (open circles). Solid symbols indicate the probe elevations. Probes labeled B, E, and $H$ included temperature sensors. The temperature history of probe $B$ is shown as representative of the first 20 hours. 


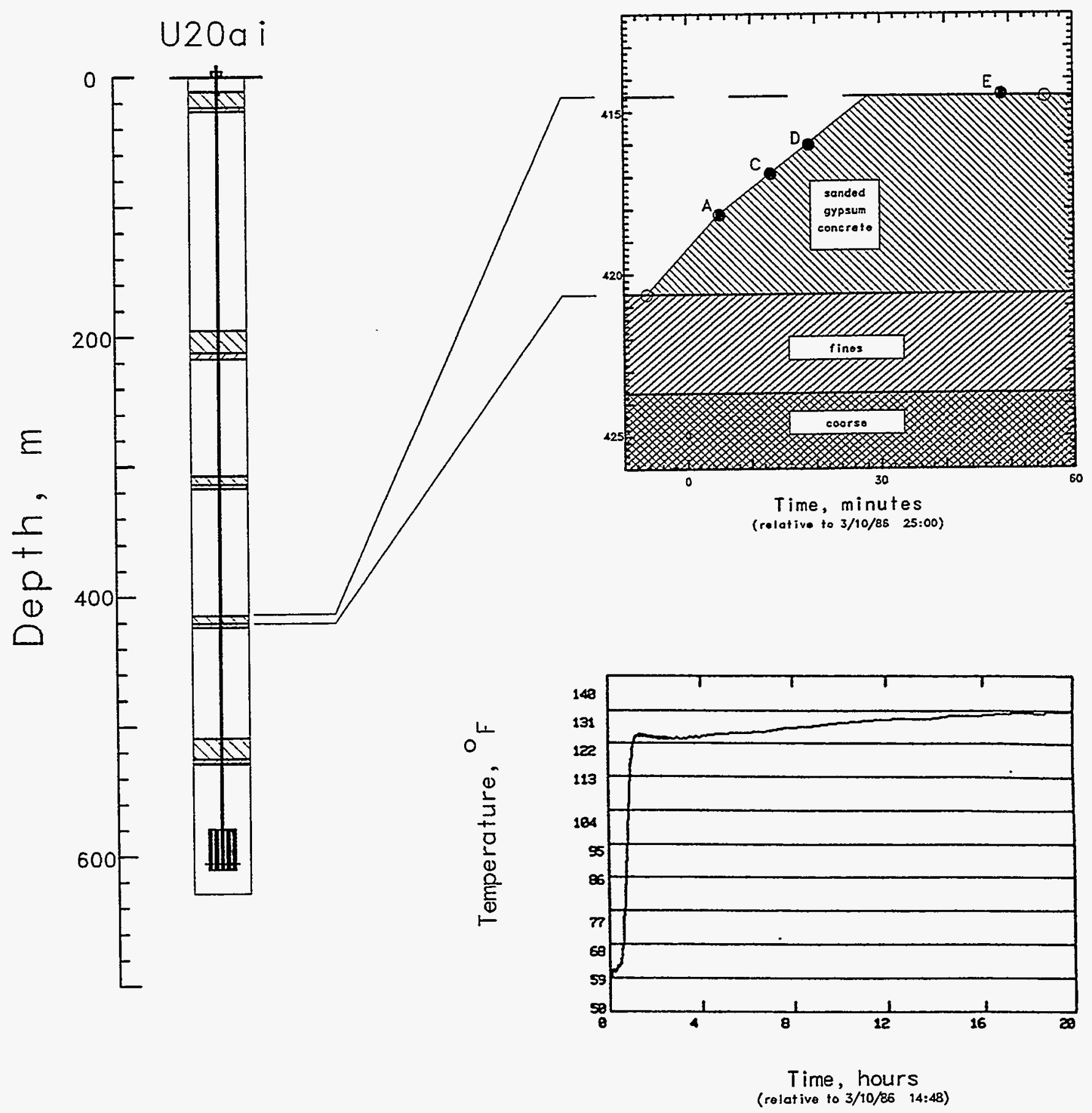

Figure 2.2 Sanded gypsum emplacement for the second plug. The upper and lower plug boundaries were determined with a tag line (open circles). Solid symbols indicate the probe elevations. Probe labeled $B$ included only a temperature sensor and is not shown in the grout level plot. It was located midway between probes $\mathrm{A}$ and $\mathrm{C}$. 

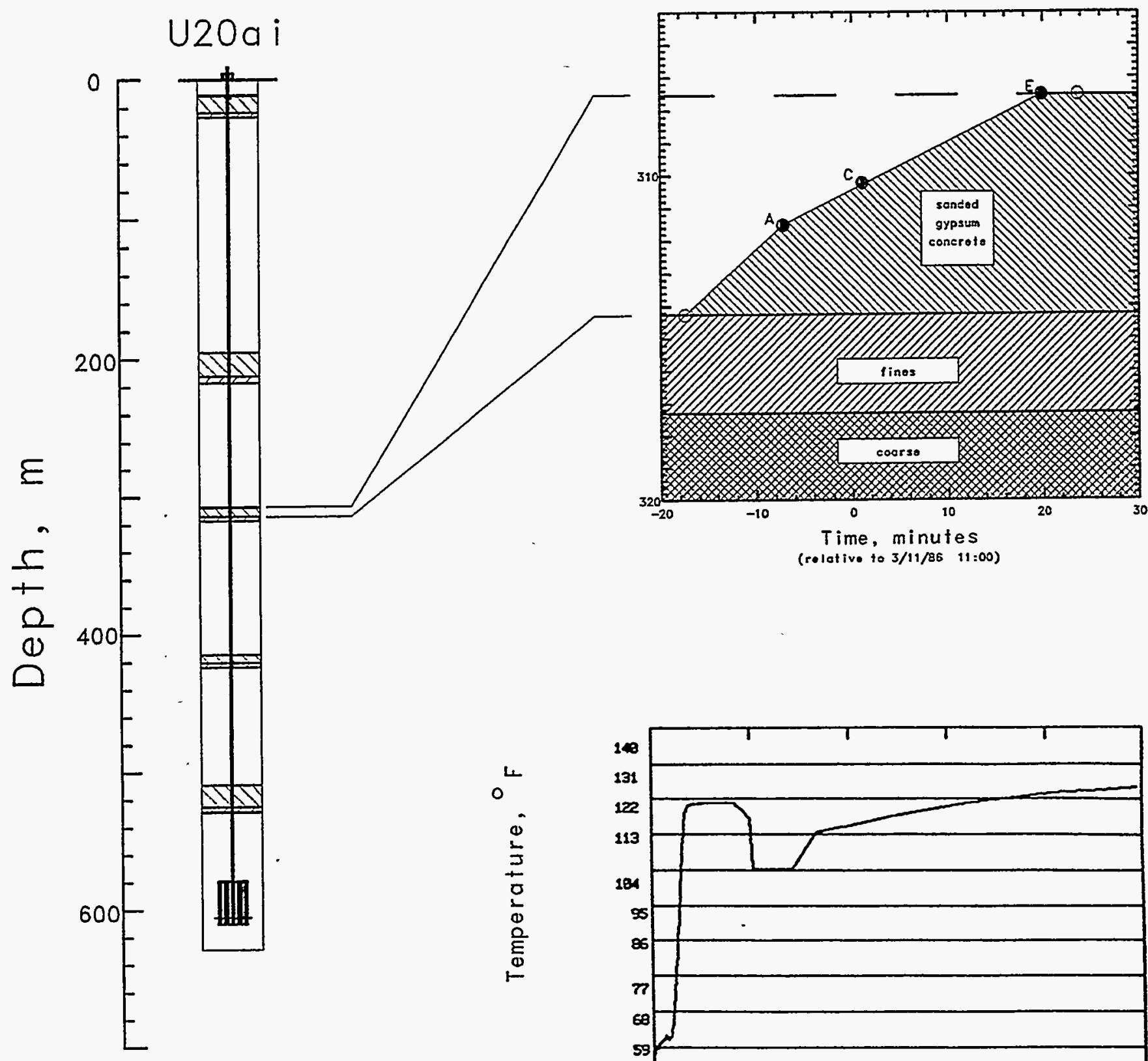

Time, minutes

(rolative to 3/11/86 11:00)

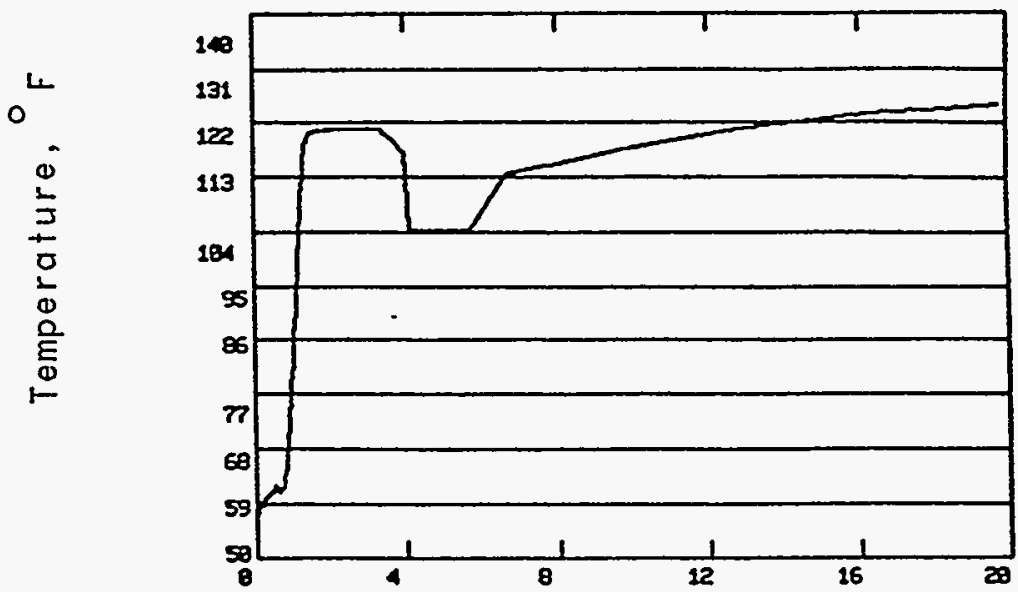

Time, hours

(relotivo to $3 / 11 / 86 \quad 11: 29$ )

Figure 2.3 Sanded gypsum emplacement for, the third plug. The upper and lower plug boundaries were determined with a tag line (open circles). Solid symbols indicate the probe elevations. Probe labeled $B$ included a only temperature sensor and is not shown in the grout level plot. It was located midway between probes $A$ and $C$. The dip in temperature near the four-hour point of the record is due to grouting of the emplacement pipe. 

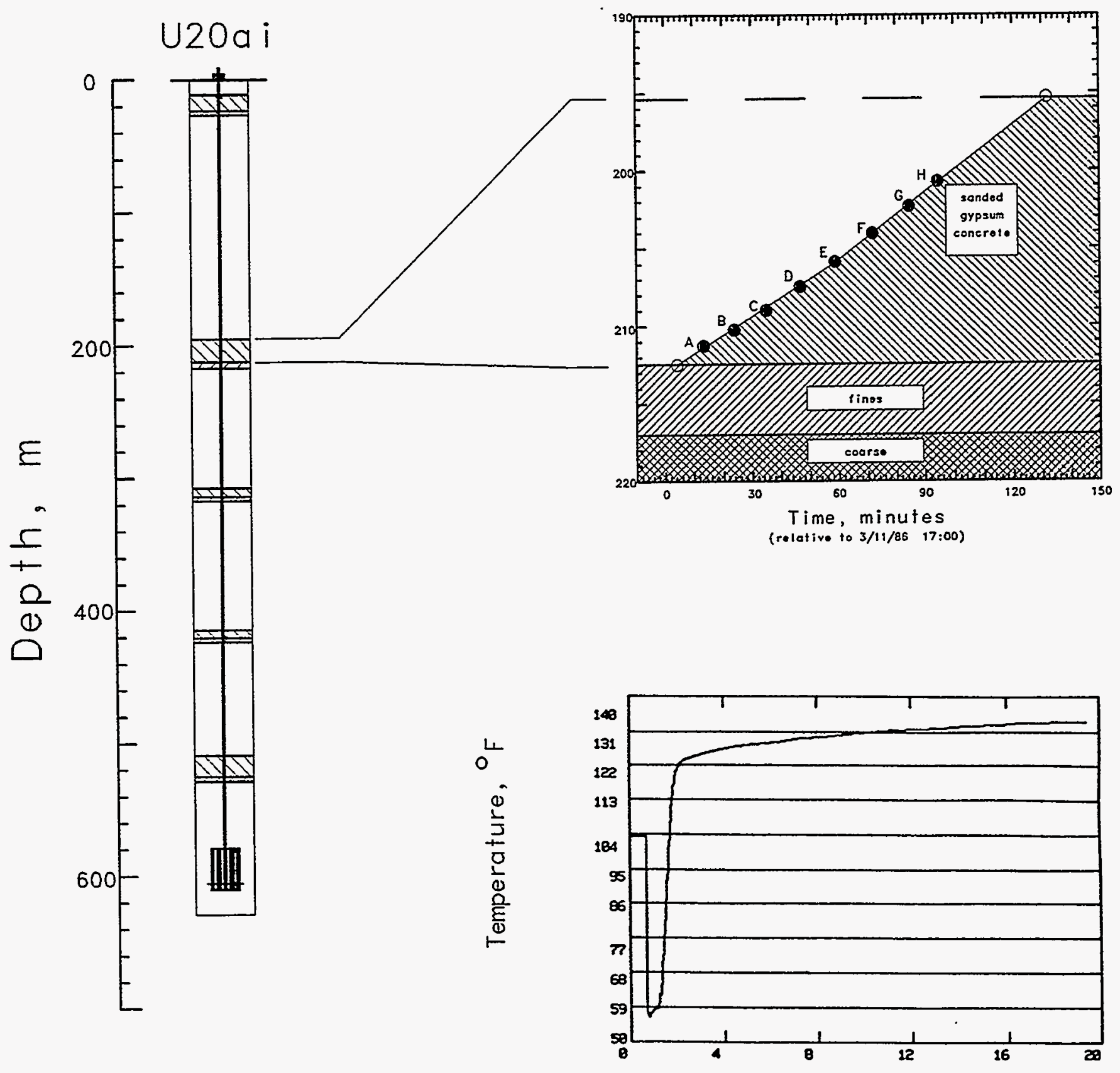

Time, hours

(relative to $3 / 11 / 86 \quad 17: \infty$ )

Figure 2.4 Sanded gypsum emplacement for the fourth plug. The upper and lower plug boundaries were determined with a tag line (open circles). Solid symbols indicate the probe elevations. Probes labeled B, D, and F included temperature sensors. The temperature history of probe $F$ is shown as representative of the first 20 hours. The initial temperature level (about 104 degrees F) is unexplained. 

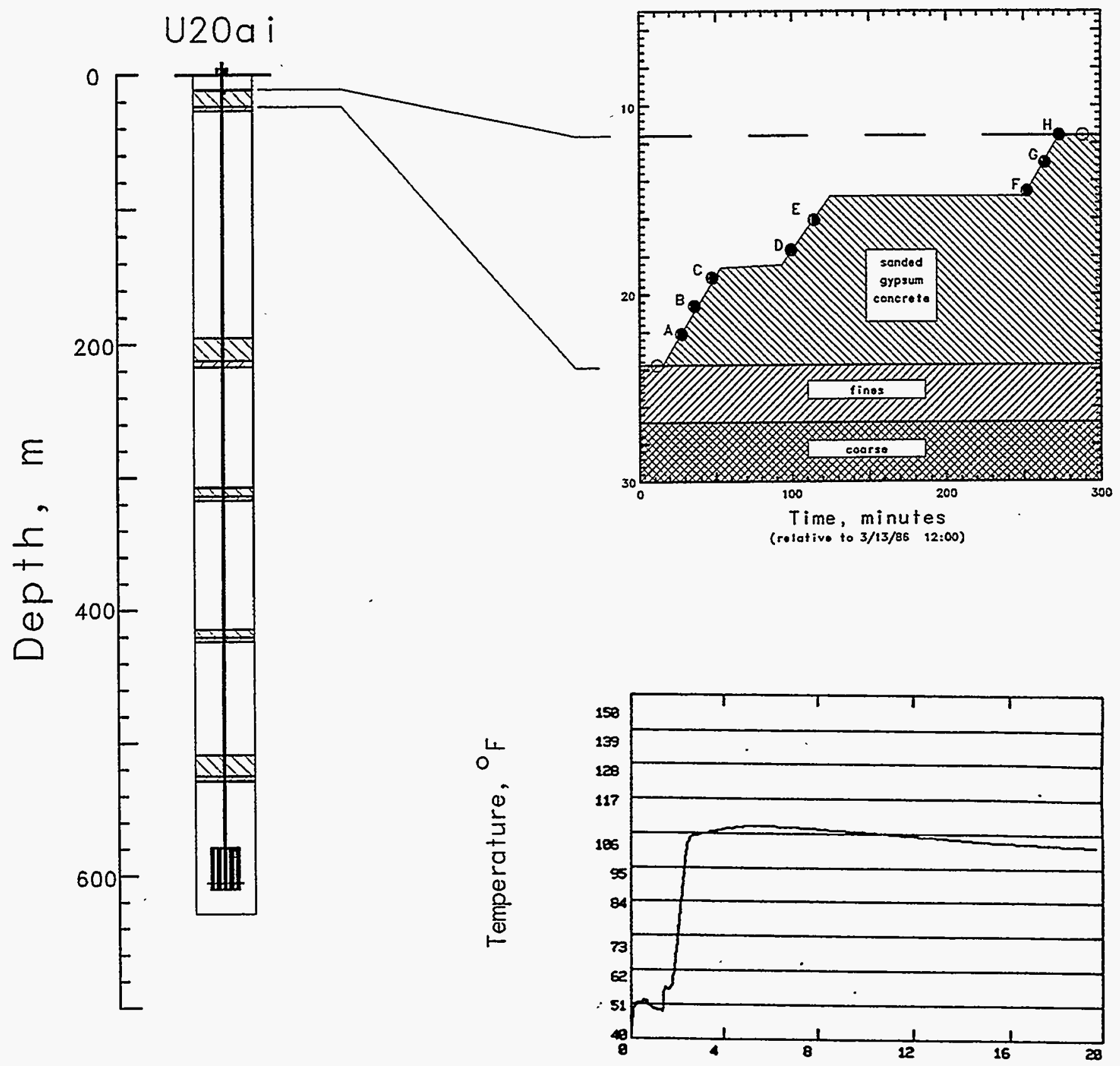

Time, hours (ralative to $3 / 13 / 86$ 12:13)

Figure 2.5 Sanded gypsum emplacement for the fifth plug. The upper and lower plug boundaries were determined with a tag line (open circles). Solid symbols indicate the probe elevations. Probes labeled $B, D$, and $F$ included temperature sensors. The temperature history of probe $D$ is shown as representative of the first 20 hours. 


\section{Stemming Performance}

All signals from stations at depths greater than $31 \mathrm{~m}$ in the emplacement hole were lost at about $2 \mathrm{~s}$ after detonation. This loss was most likely due to cable breakage caused by the excessive motion associated with the explosion. All recording was terminated 32 hours after the detonation.

\subsection{Radiation and Pressure}

As indicated in Figure 1.4, pressure and radiation were monitored in the region below each of the upper four SGC plugs.

Pressure and radiation histories, from a few seconds before detonation until recording termination or station failure, are displayed in Figures 3.1-3.5. The radiation signal from station 31 (in the bottom plug) went beyond band edge prior to $2 \mathrm{~s}$ while stations at shallower depths show little, if any, indication of radiation arrivals. At station 32 (below the second SGC plug) a large pressure pulse arrives at about $0.1 \mathrm{~s}$ and peaks at about $0.5 \mathrm{~s}$ with a pressure change of around 22 psi. Stations at shallower depths show a different behavior, suggesting that the early time pressure history of the stemming column may be that of compaction and dilatation due to the passage of the shock wave.

All pressure and radiation data are consistent with satisfactory containment. 


\subsection{Motion}

Recording on magnetic tapes containing the data from all stations in the SGC plugs (except station 31), the ground surface and on the surface casing was halted at about $2 \mathrm{~s}$ by the strong explosion-induced motion of the recording trailer. Stations 24 (in the top plug), 25 (on the surface casing), and 35 (in the stemming below the top plug) were the only stations in the emplacement hole to survive beyond 2.5 seconds. Although station 24 and 25 survived, the tapes recording the signals were halted at that time precluding further explosion-induced motion from these stations. Subsequently, the tapes were restarted manually when the field crew re-entered the trailer.

Figures 3.6-3.16 show the explosion-induced vertical acceleration measured in the coarse stemming and in the stemming plugs. Station 25 monitored the vertical acceleration and velocity of the surface casing while station 61 monitored the vertical motion of the ground surface at a depth of $0.91 \mathrm{~m}$ and a horizontal range of $15.24 \mathrm{~m}$ from SGZ. Characteristics of the motion and motion transducers are given in tables 3.1-3.3.

\subsection{Collapse}

All three of the EXCOR cables were active post-shot. The time variation of the position of the deepest end of the cables as a function of time is shown in Figure 3.17. Subsurface collapse appears to have progressed upwards to a depth of about $190 \mathrm{~m}$ (close to the top of the fourth plug). A slight increase in pressure (about $0.1 \mathrm{psi}$ ) was registered at station 35 at about $9485 \mathrm{~s}$ and is plotted in figure 3.17 as a circle. The acceleration history of station 35 is superimposed (without amplitude scale) on figure 3.17 at the approximate elevation of that station. The acceleration seen corresponds to the collapse history reported by the EXCOR and suggests that the pressure change is the result of a slight stemming shift and that the stemming remains othenwise in place below the top plug.

The motion sensed at stations 24, 35, and 61 during the collapse phase (about 2 hours and 38 minutes) was of too low a magnitude to be meaningfully integrated, so only the measured signals are shown. The proximity switch array (station 87 ) registered no change of relative position of the top plug and surface casing at any time and the data from this station are not shown. 
Table 3.1 Summary of Motion

\begin{tabular}{|c|c|c|c|c|c|c|}
\hline Gauge & $\begin{array}{l}\text { Slant Range } \\
\text { (m) }\end{array}$ & $\begin{array}{l}\text { Arrival Time } \\
\text { (ms) }\end{array}$ & $\begin{array}{c}\text { Peak } \\
\text { Acceleration } \\
\text { (g) }\end{array}$ & $\begin{array}{l}\text { Peak } \\
\text { Velocity } \\
\text { (m/s) }\end{array}$ & $\begin{array}{l}\text { Peak } \\
\text { Displacement } \\
(\mathrm{m})\end{array}$ & $\begin{array}{l}\text { Residual } \\
\text { Displacement } \\
\text { (cm) }\end{array}$ \\
\hline $21 a v$ & 190 & 74 & $22.4,48.0$ & 21.2 & 5.3 & (a) \\
\hline 21uv & & - & - & 20.7 & 4.3 & (a) \\
\hline $22 a v$ & 297 & 115 & $8.0,3.6$ & 5.8 & 2.1 & (a) \\
\hline $22 u v$ & & - & - & 5.7 & 2.0 & (a) \\
\hline $23 a v$ & 401 & 160 & $2.2,1.0$ & 3.6 & 1.02 & (a) \\
\hline 23uv & & (b) & - & - & - & - \\
\hline $24 a v$ & 590 & $139(c), 288$ & $3.54,8.3^{(d)}$ & 5.1 & 2.65 & (a) \\
\hline $24 u v$ & & - & - & 4.9 & 2.45 & (a) \\
\hline $25 a v$ & 608 & $143^{(c)}, 296$ & $4.1,8^{(d)}$ & 5.7 & 2.60 & (a) \\
\hline 25 UV & & - & - & 4.7 & 2.31 & (a) \\
\hline $31 \mathrm{av}$ & 91 & $31(c), 41(e)$ & (a) & - & - & - \\
\hline $32 a v$ & 142 & $41(c), 75$ & 53 & 23.5 & $14.3^{(f)}$ & (a) \\
\hline $33 a v$ & 218 & $52(c), 83$ & 8 & 7.8 & 3.4 & \\
\hline $34 a v$ & 387 & $93(c), 156$ & 4.4 & 5.0 & 2.3 & \\
\hline $35 u v$ & 577 & 139 (c), 230 & $5.1^{(g)}, 24^{(d)}$ & 5.1 & 2.56 & -34 \\
\hline $61 a v$ & 608 & 310 & $5.0,9.8^{(d)}$ & 5.0 & 2.58 & (a) \\
\hline 61uv & & - & - & 5.0 & 2.50 & (a) \\
\hline
\end{tabular}
(a) Signal lost before this value could be attained.
(b) Channel lost before this datum was attained.
(c) Emplacement pipe- or strongback-stemming interaction.
(d) Slap-down peak.
(e) Signal was lost at ground motion arrival.
(f) Peak of displacement not reached. 
Table 3.2 Accelerometer Characteristics

\begin{tabular}{|c|c|c|c|}
\hline Gauge & $\begin{array}{l}\text { Natural Frequency } \\
(\mathrm{Hz})\end{array}$ & Damping Ratio & $\begin{array}{c}\text { System Range } \\
\text { (g's) }\end{array}$ \\
\hline $21 a v$ & 1020 & 0.65 & 600 \\
\hline $22 a v$ & 880 & 0.65 & 200 \\
\hline $23 a v$ & 300 & 0.85 & 50 \\
\hline $24 a v$ & 275 & 0.80 & 20 \\
\hline $25 a v$ & 290 & 0.75 & 20 \\
\hline $31 a v(a)$ & 30,000 & 0.002 & 5000 \\
\hline $32 a v(a)$ & NA & NA & 500 \\
\hline $33 a v(a)$ & NA & NA & 250 \\
\hline $34 a v(a)$ & 2500 & 0.7 & 25 \\
\hline $35 a v(a)$ & 2500 & .0 .7 & 25 \\
\hline $61 \mathrm{av}$ & 590 & 0.65 & 36 \\
\hline
\end{tabular}

(a) manufacturer specifications

Table 3.3 Velocimeter Characteristics

\begin{tabular}{|c|c|c|c|c|c|}
\hline Gauge & $\begin{array}{c}\text { Natural } \\
\text { Frequency } \\
(\mathrm{Hz})\end{array}$ & $\begin{array}{l}\text { Time to } 0.5 \\
\text { Amplitude } \\
\text { (s) }\end{array}$ & $\begin{array}{c}\text { Calibration } \\
\text { Temperature } \\
\left({ }^{\circ} \mathrm{C}\right)\end{array}$ & $\begin{array}{c}\text { Operate } \\
\text { Temperature } \\
\left({ }^{\circ} \mathrm{C}\right)\end{array}$ & $\begin{array}{c}\text { System } \\
\text { Range } \\
\text { (m/s) }\end{array}$ \\
\hline 21uv & 3.823 & 30.37 & 26.93 & 28.03 & 60 \\
\hline $22 u v$ & 4.068 & 18.51 & 26.12 & 23.01 & 32 \\
\hline 23uv & 3.308 & 14.18 & 26.62 & 23.67 & 20 \\
\hline 24 uv & 3.463 & 9.76 & 26.57 & 21.97 & 12 \\
\hline 25 uv & 3.619 & 8.80 & 26.51 & 10.47 & 12 \\
\hline 61 uv & 3.553 & 9.46 & 24.76 & 8.41 & 12 \\
\hline
\end{tabular}




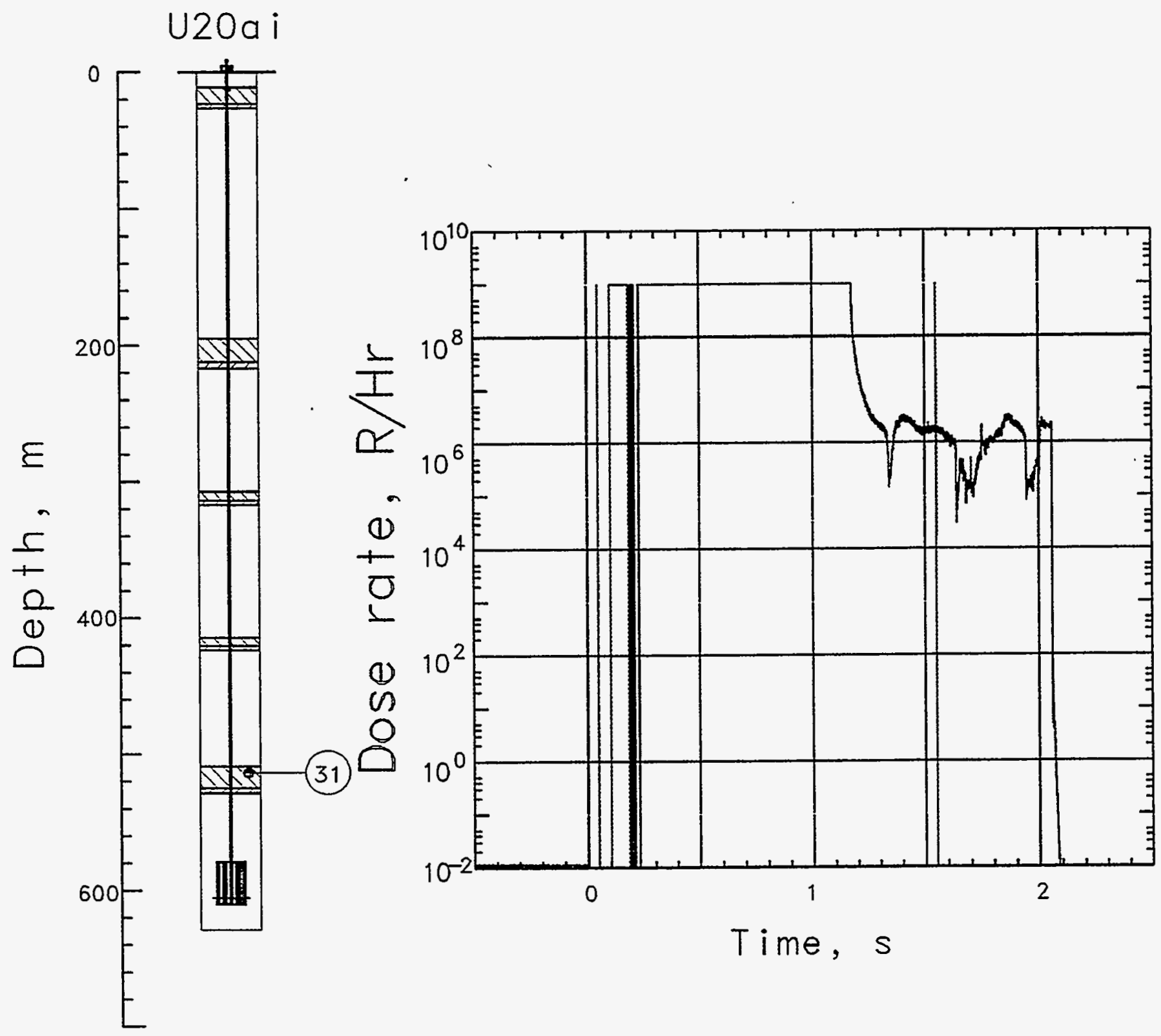

Figure 3.1 Radiation measured in the first SGC plug (station 31 at $516.6 \mathrm{~m}$ depth). Station signals were lost at about $2 \mathrm{~s}$ after detonation. There was no pressure transducer installed at this station. 

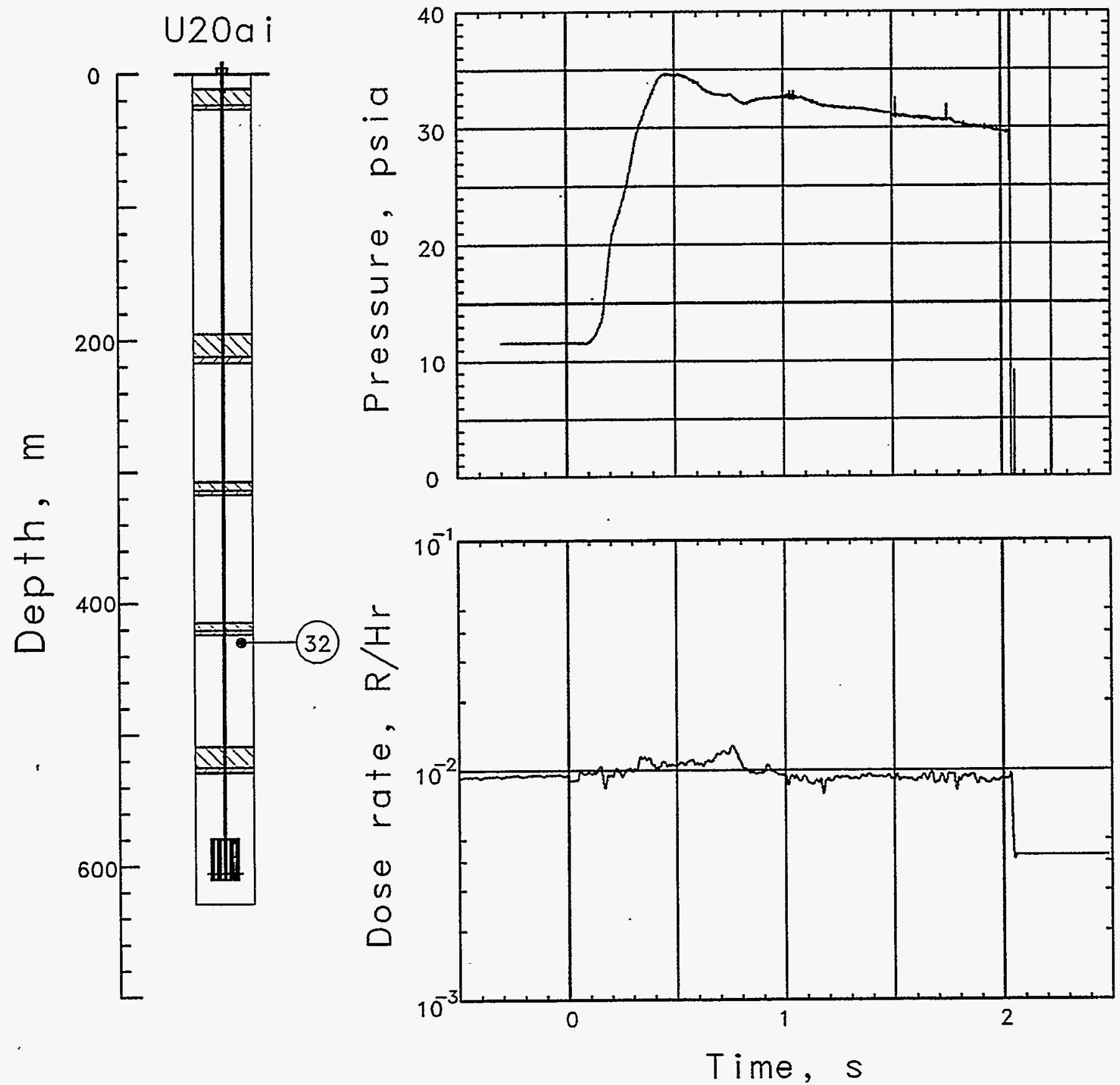

Figure 3.2 Pressure and radiation measured in the course stemming below the second SGC plug (station 32 at $466.3 \mathrm{~m}$ depth). Station signals were lost at about $2.1 \mathrm{~s}$ after detonation. 

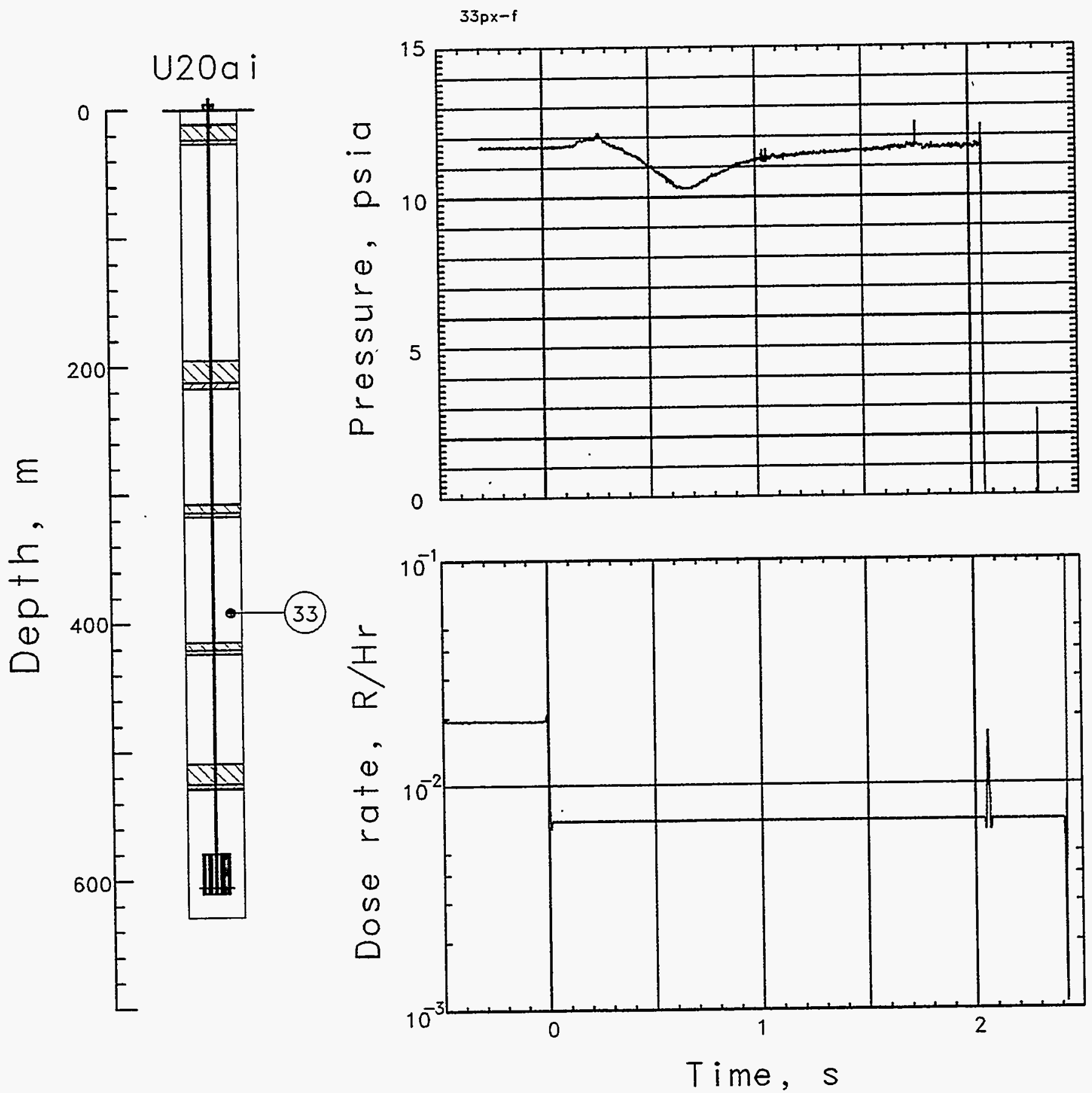

Figure 3.3 Pressure and radiation measured in the coarse stemming below the third SGC plug (station 33 at $390.1 \mathrm{~m}$ depth). Station signals were lost at about $2.1 \mathrm{~s}$ after detonation. 

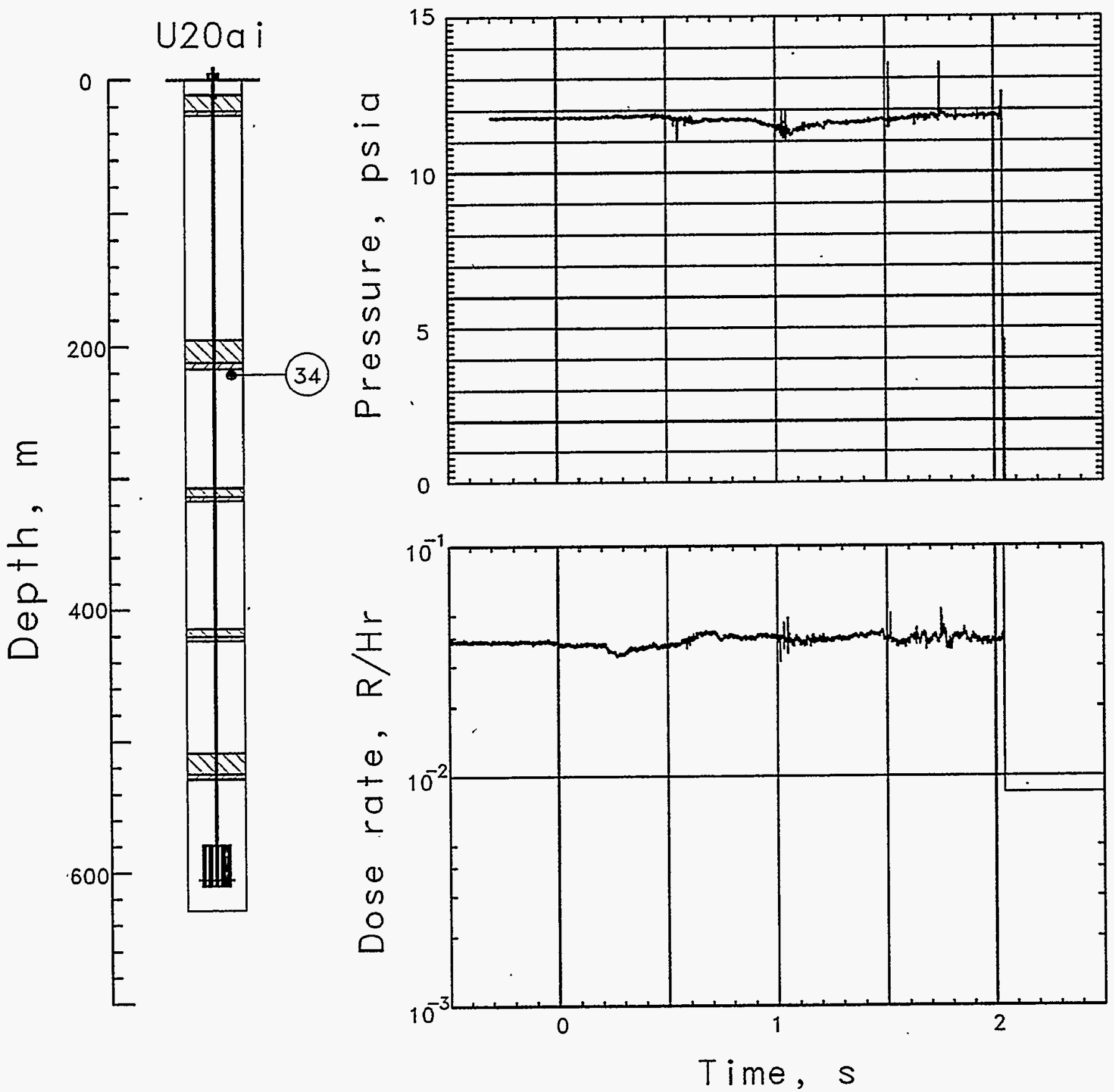

Figure 3.4 Pressure and radiation measured in the coarse stemming below the fourth SGC plug (station 34 at $221.0 \mathrm{~m}$ depth). Station signals were lost at about $2.1 \mathrm{~s}$ after detonation. 


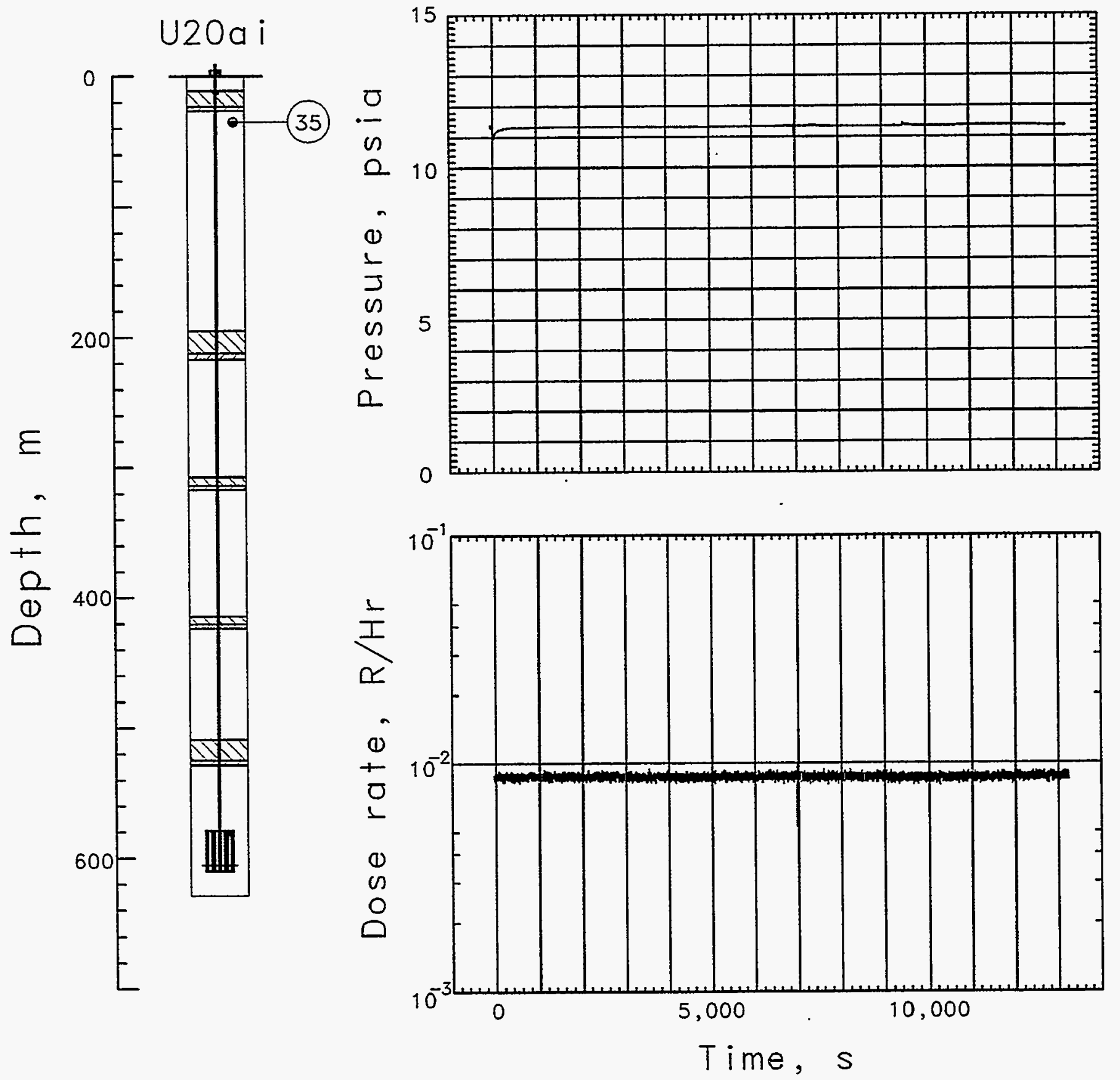

Figure 3.5 Pressure and radiation measured in the coarse stemming below the fifth SGC plug (station 35 at $31.4 \mathrm{~m}$ depth). The pressure drop at zero time is due to shockinduced ground motion and the jump in pressure at about $9500 \mathrm{~s}$ is associated with the subsurface collapse. 


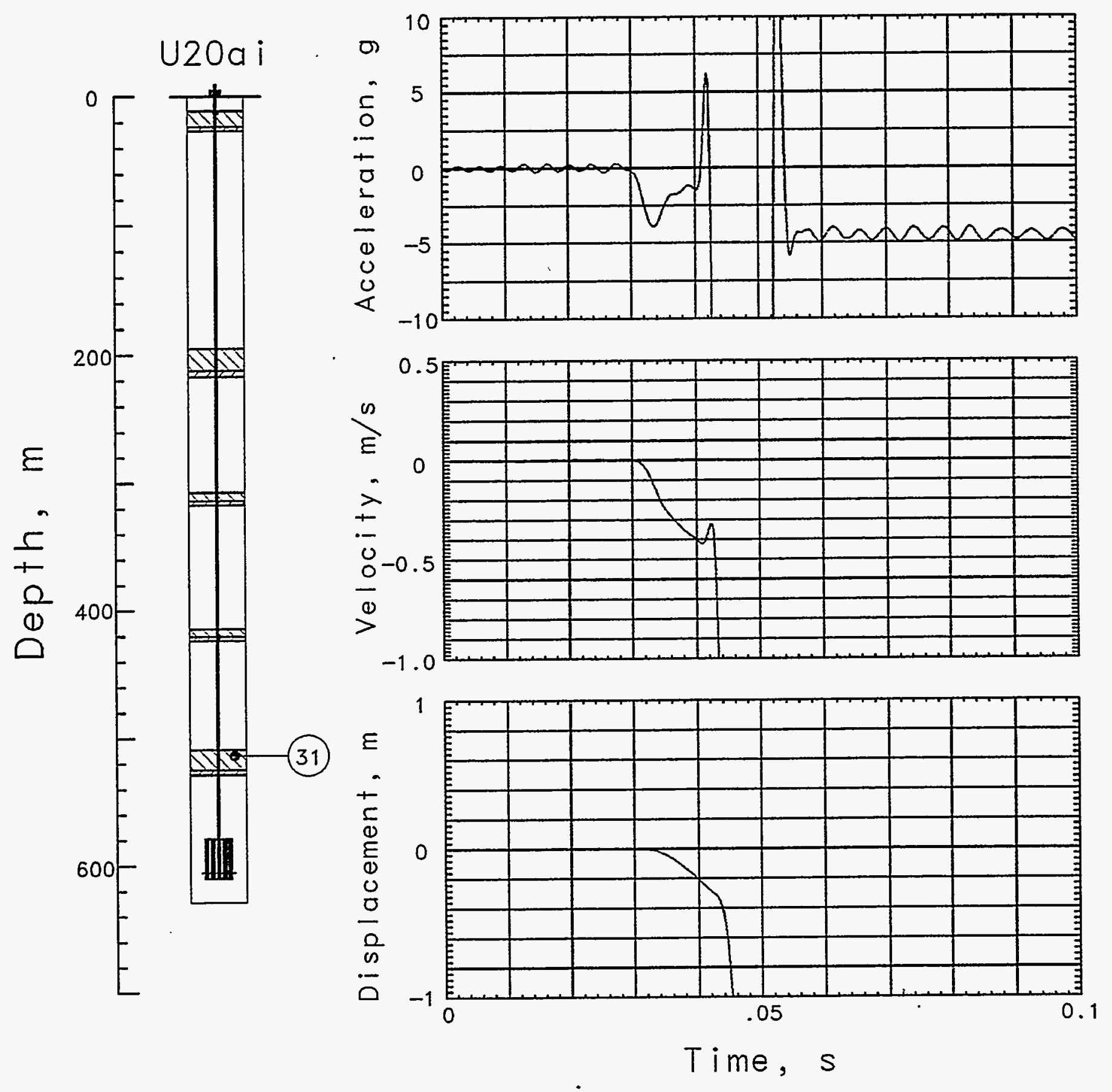

Figure 3.6 Explosion-induced vertical motion of the bottom plug at a depth of $516.6 \mathrm{~m}$ (station 31). The data are invalid after $42 \mathrm{~ms}$. The anomalous negative-going initial motion is unexplained. 


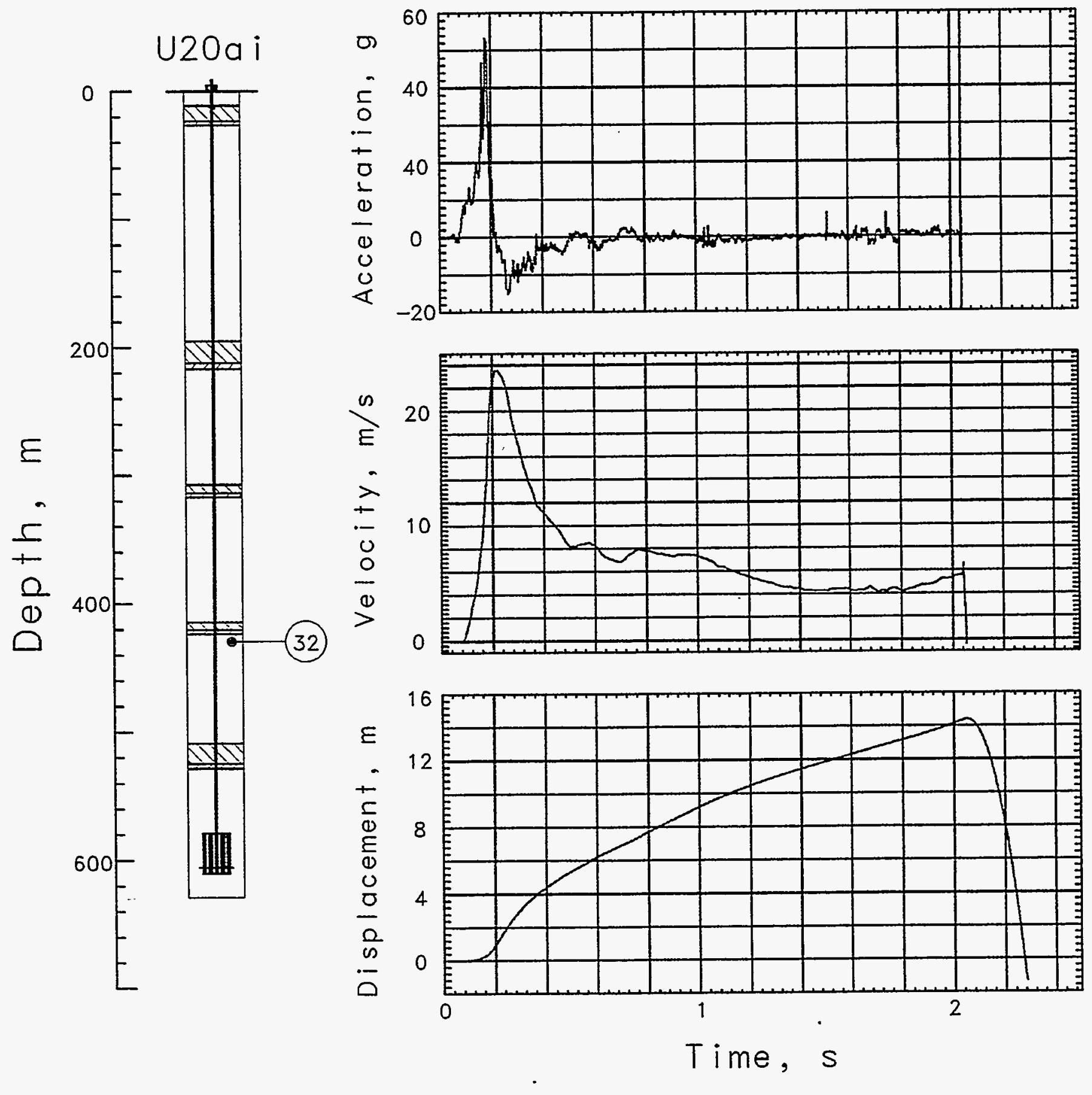

Figure 3.7 Explosion-induced vertical motion in the coarse stemming of the emplacement hole at a depth of $466.3 \mathrm{~m}$ (station 32). Station signals were lost at about $2.1 \mathrm{~s}$ after detonation. 


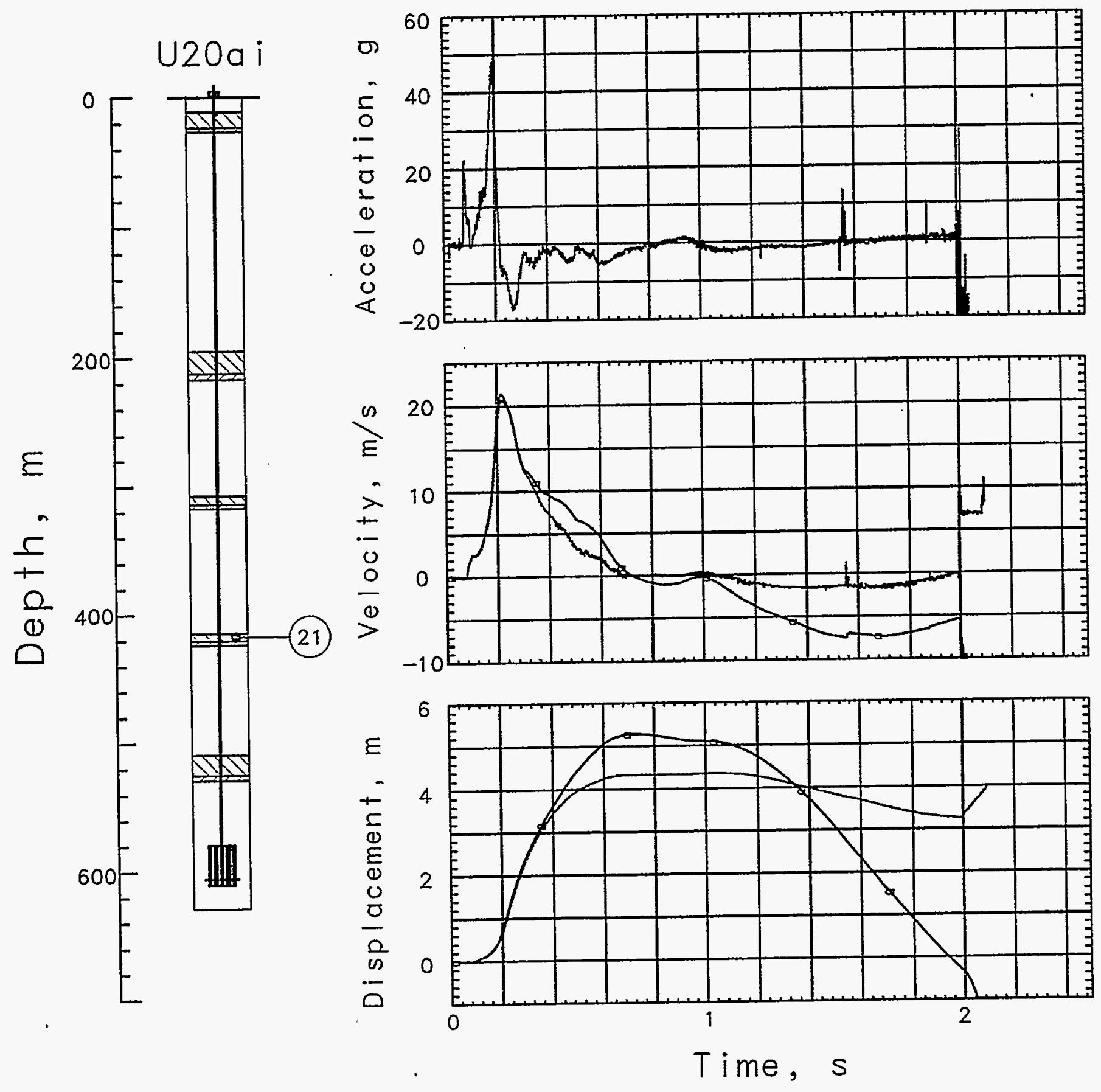

Figure 3.8 Explosion-induced vertical motion of the second plug at a depth of $417.6 \mathrm{~m}$ (station 21). Station signals were lost at about $2.0 \mathrm{~s}$ after detonation. Data records annotated with an "a" were obtained from an accelerometer. 


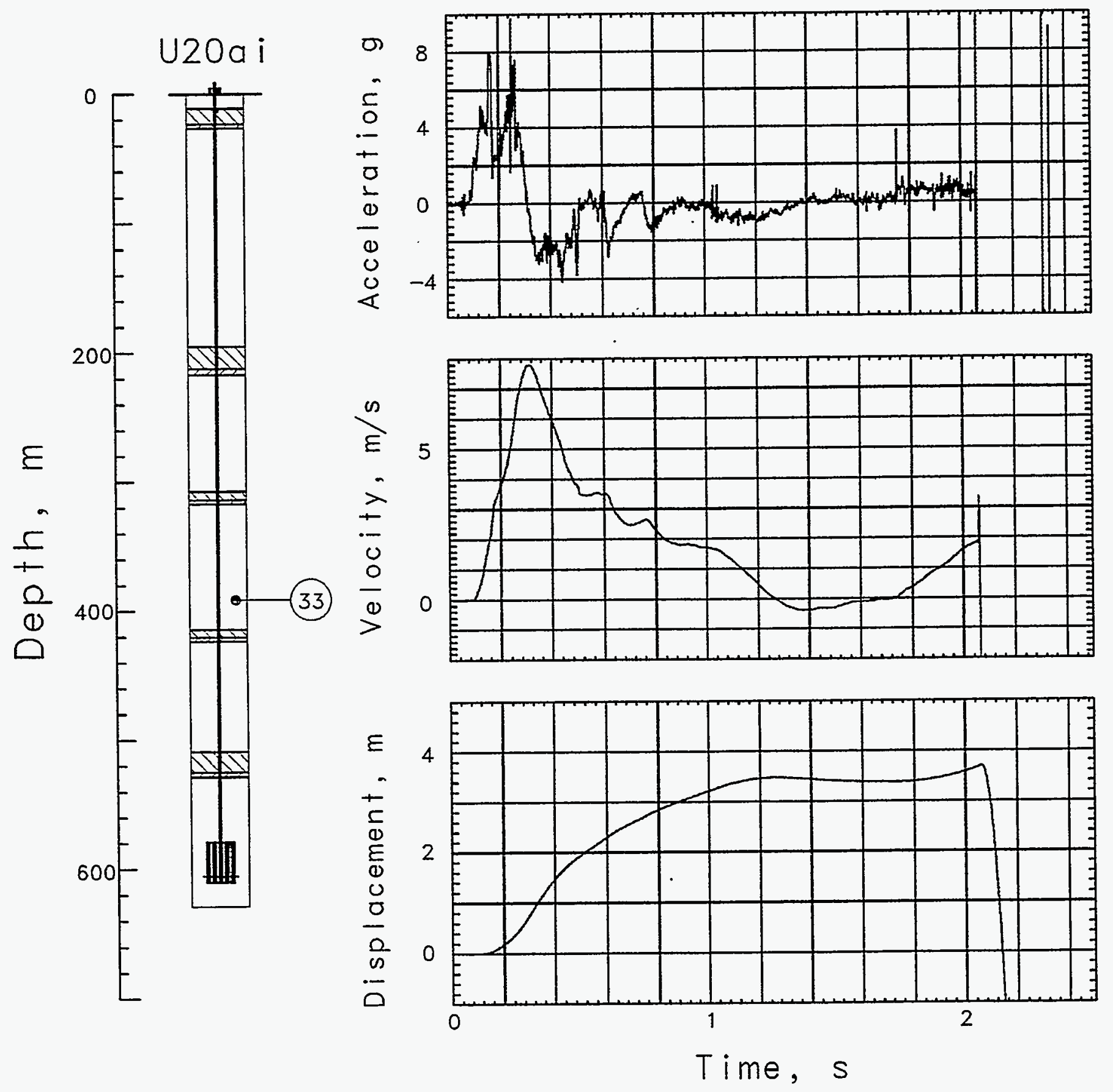

Figure 3.9 Explosion-induced vertical motion in the coarse stemming of the emplacement hole at a depth of $390.1 \mathrm{~m}$ (station 33). Station signals were lost at about $2.1 \mathrm{~s}$ after detonation. 


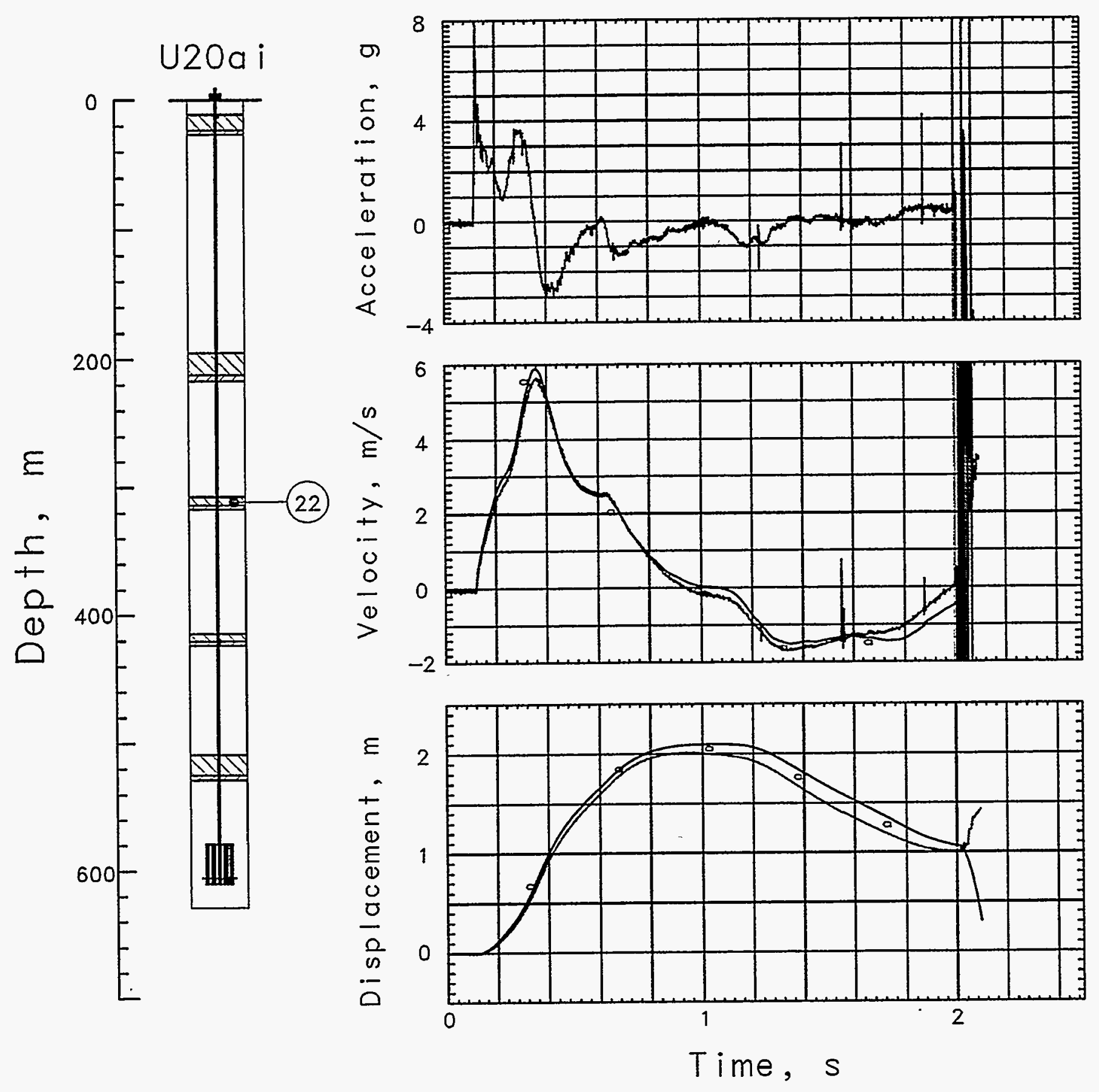

Figure 3.10 Explosion-induced vertical motion of the third plug at a depth of $310.9 \mathrm{~m}$ (station 22). Station signals were lost at about $2.0 \mathrm{~s}$ after detonation. Data records annotated with an "a" were obtained from an accelerometer. 


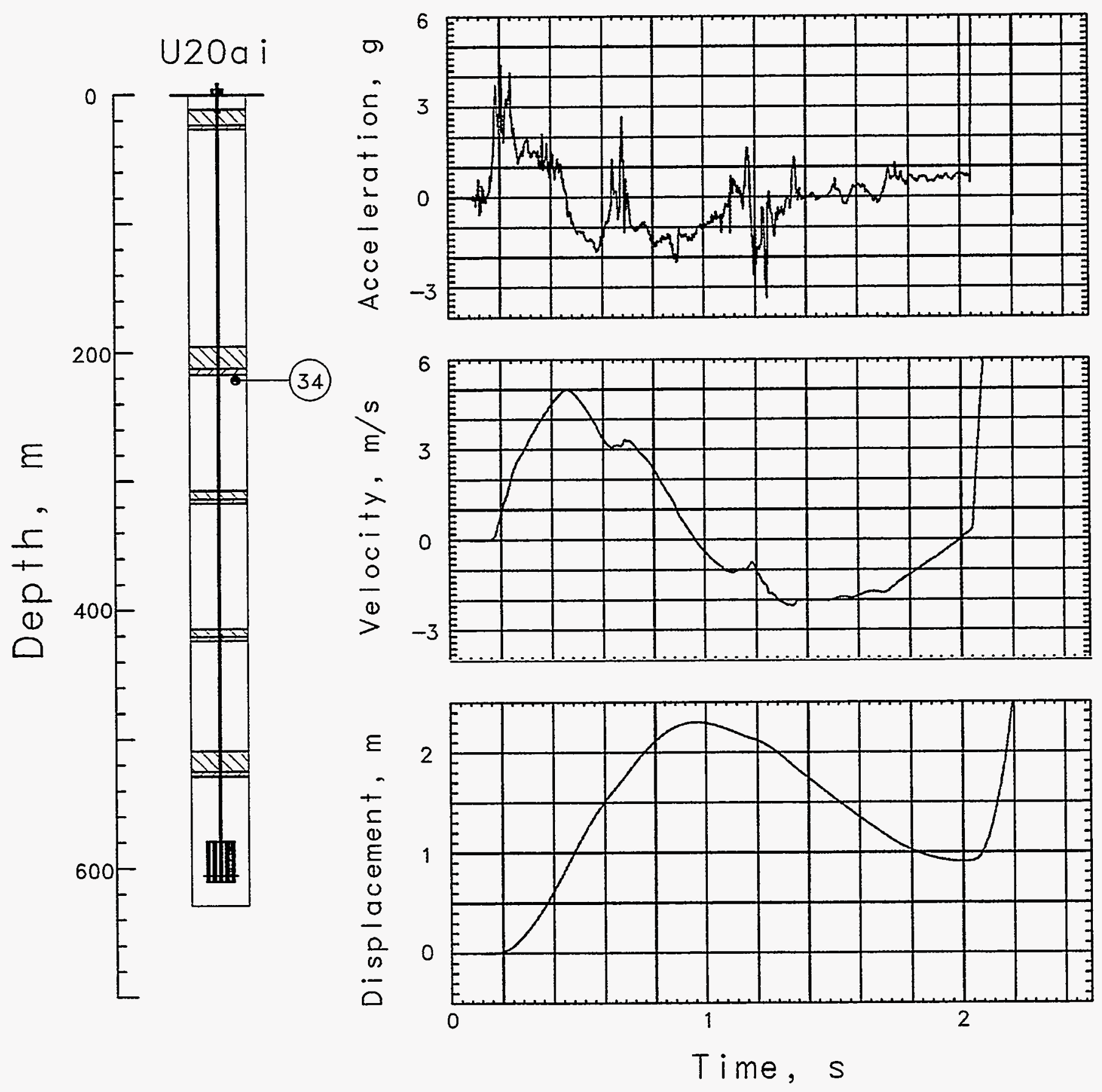

Figure 3.11 Explosion-induced vertical motion in the coarse stemming of the emplacement hole at a depth of $221.0 \mathrm{~m}$ (station 34). Station signals were lost at about $2.1 \mathrm{~s}$ after detonation. 


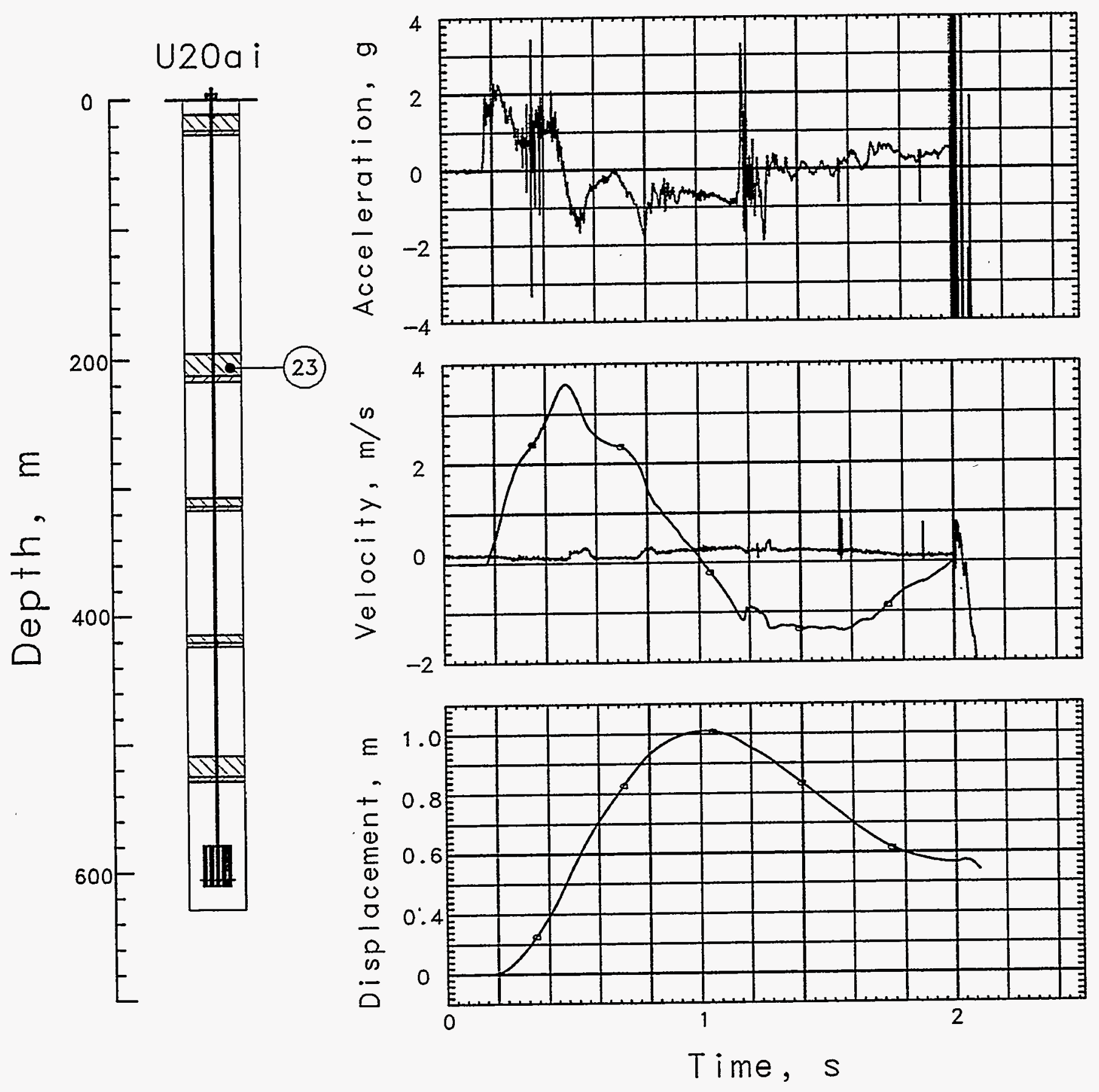

Figure 3.12 Explosion-induced vertical motion of the fourth plug at a depth of $207.3 \mathrm{~m}$ (station 23). Station signals were lost at about $2.0 \mathrm{~s}$ after detonation. Data records annotated with an "a" were obtained from an accelerometer. The associated velocimeter at this station was apparently inoperative pre-shot. 


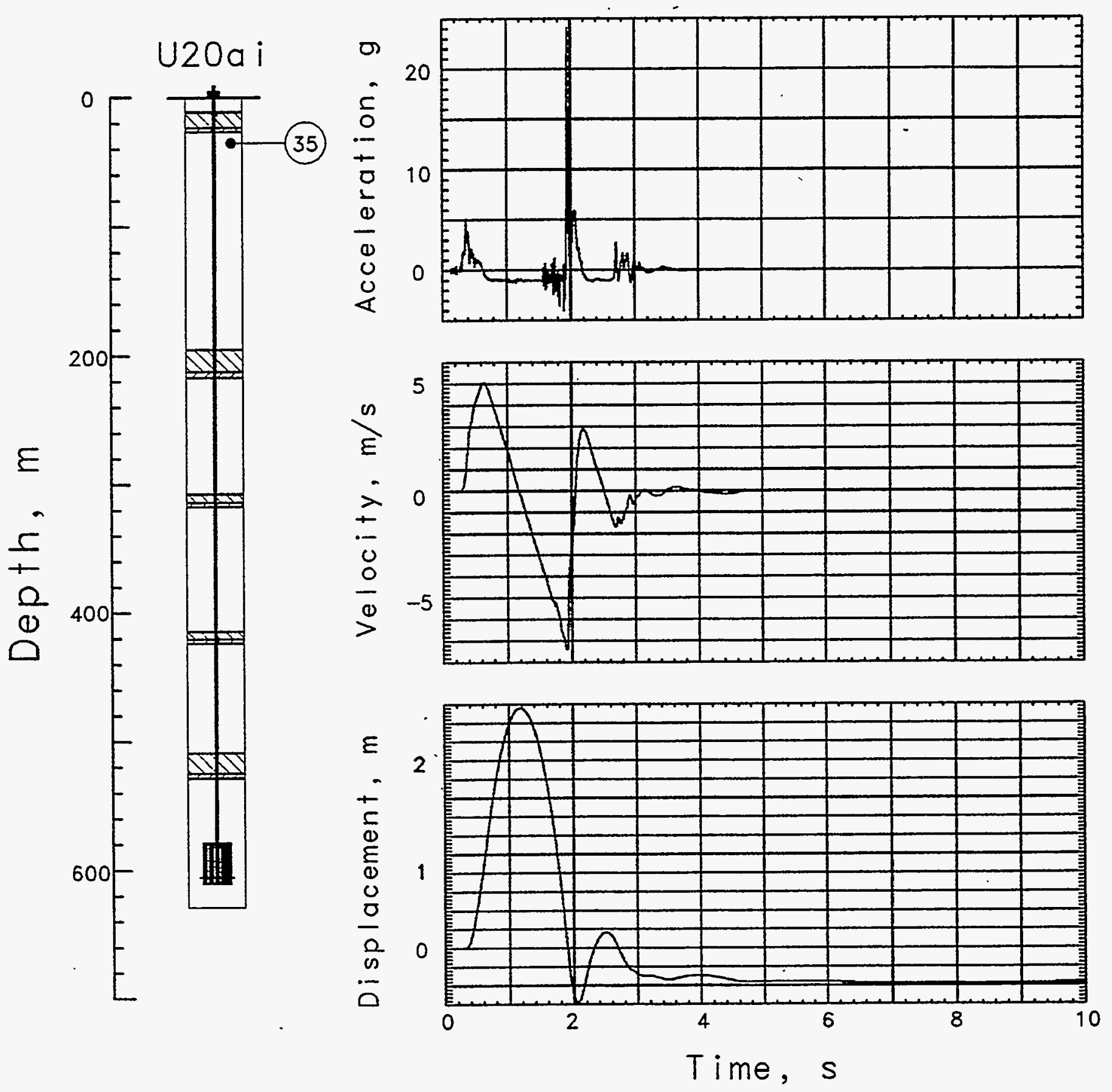

Figure 3.13 Explosion-induced vertical motion in the coarse stemming of the emplacement hole at a depth of $31.4 \mathrm{~m}$ (station 35). This is the only station for which the final explosion-induced displacement could be derived. 


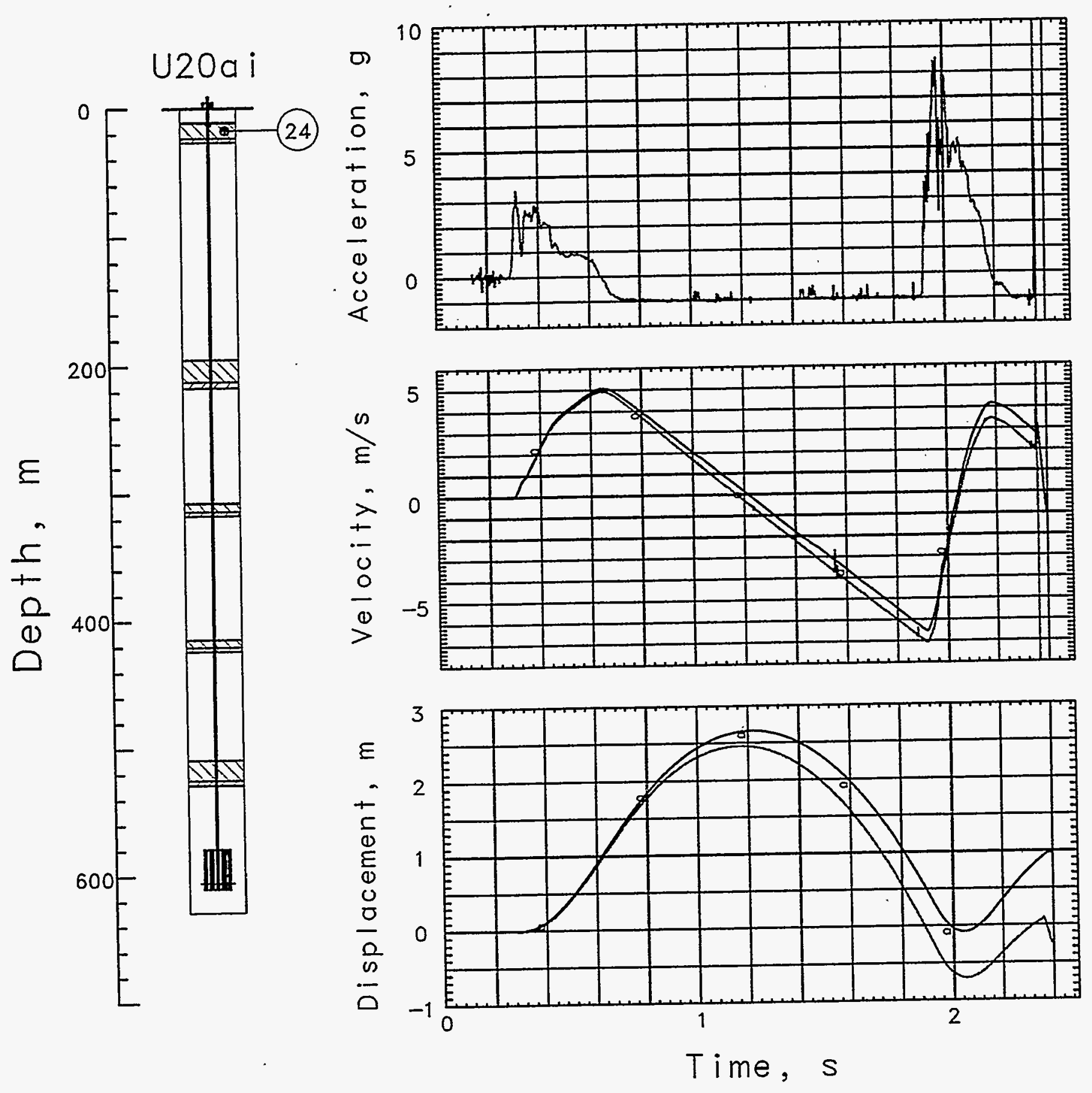

Figure 3.14 Explosion-induced vertical motion of the fifth plug at a depth of $17.7 \mathrm{~m}$ (station 24). Station signals were interrupted at about $2.4 \mathrm{~s}$ after detonation. Data records annotated with an "a" were obtained from an accelerometer: 


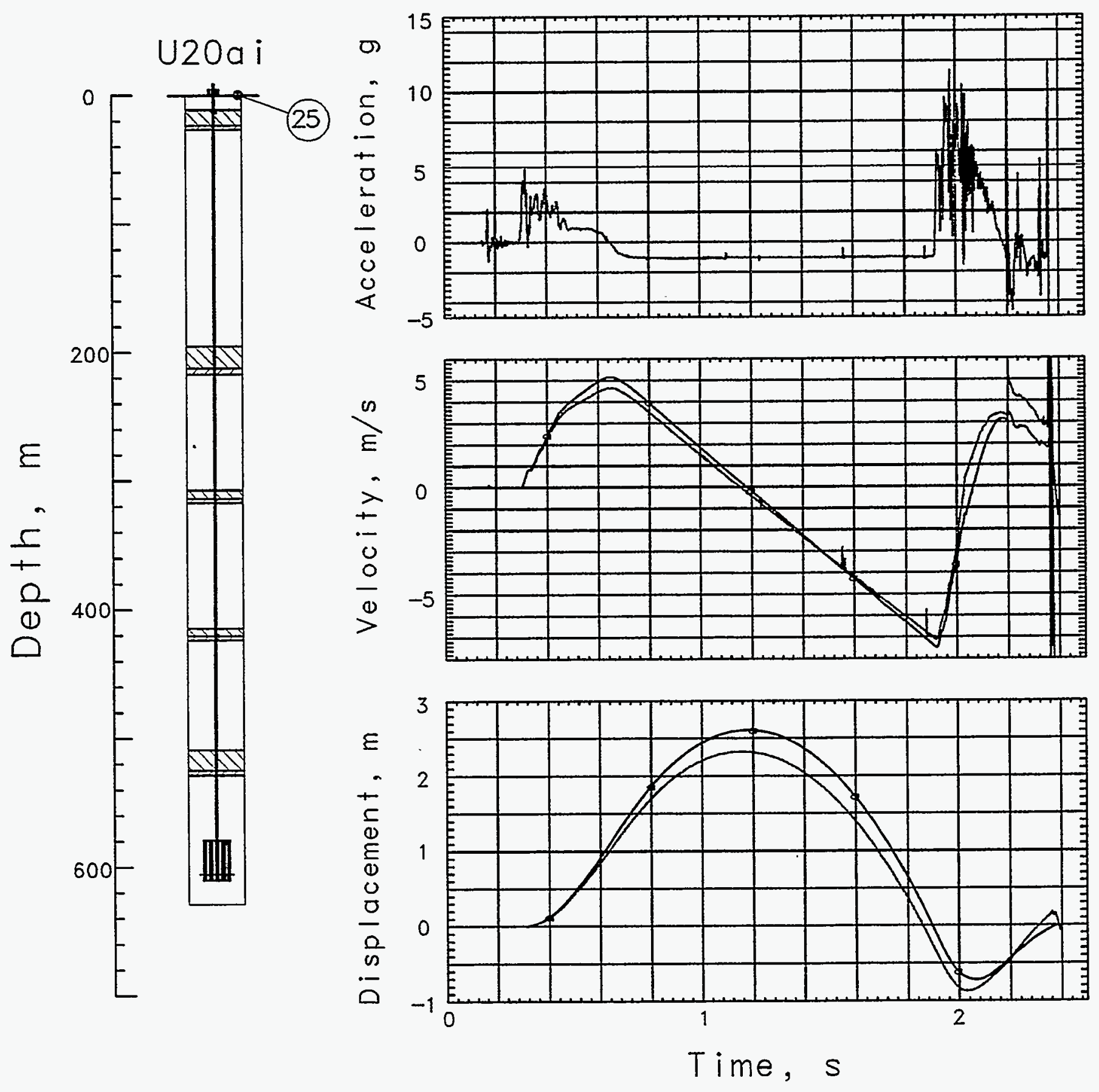

Figure 3.15 Explosion-induced vertical motion of the surface casing (station 25). Station signals were interrupted at about $2.4 \mathrm{~s}$ after detonation. Data records annotated with an "a" were obtained from an accelerometer. 

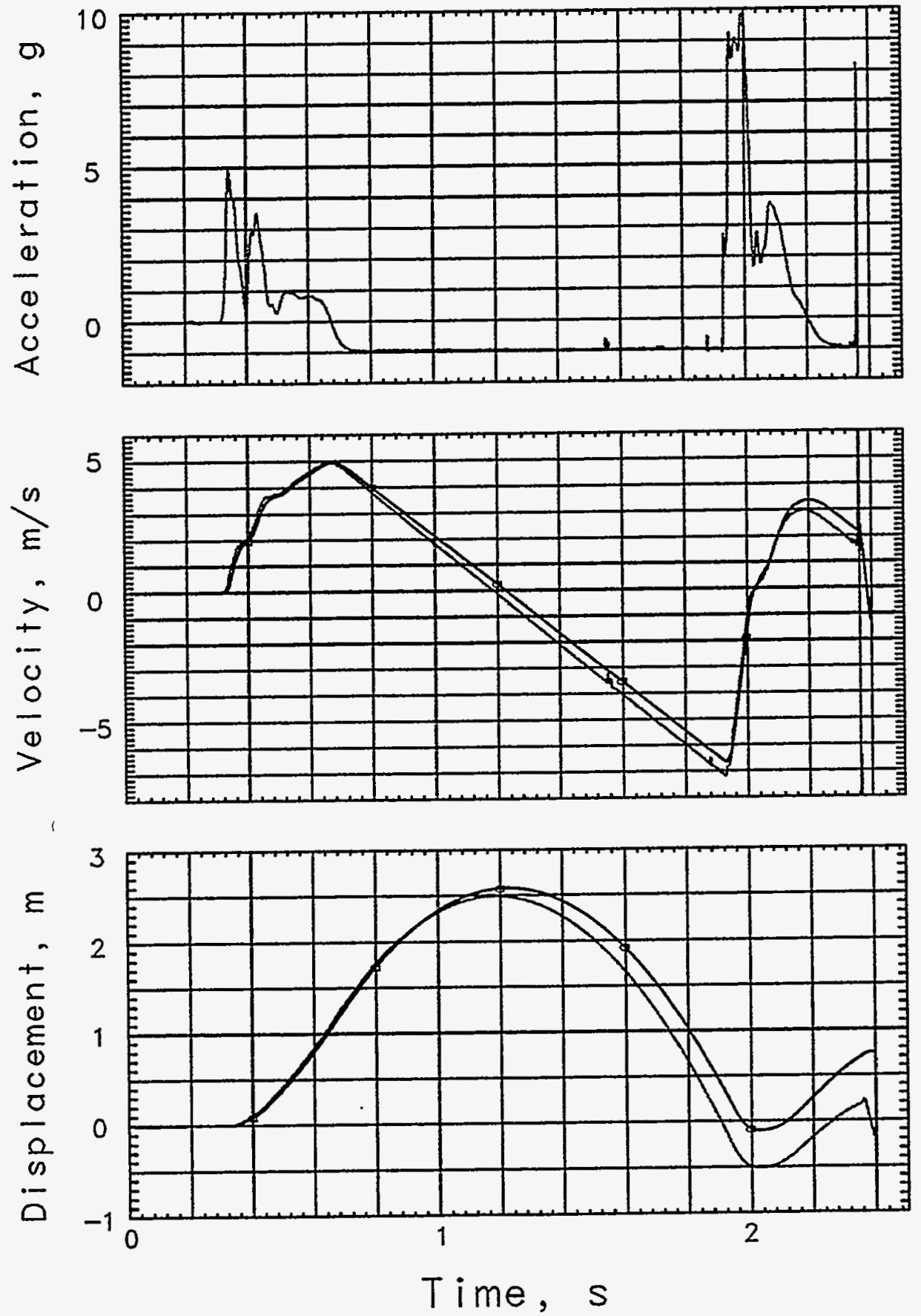

Figure 3.16 Explosion-induced vertical motion $0.91 \mathrm{~m}$ deep in the ground surface at a horizontal distance of $15.24 \mathrm{~m}$ from Surface Ground Zero (station 61 ). Station signals were interrupted at about $2.4 \mathrm{~s}$ after detonation. Data records annotated with an 'a' are derived from the accelerometer. 

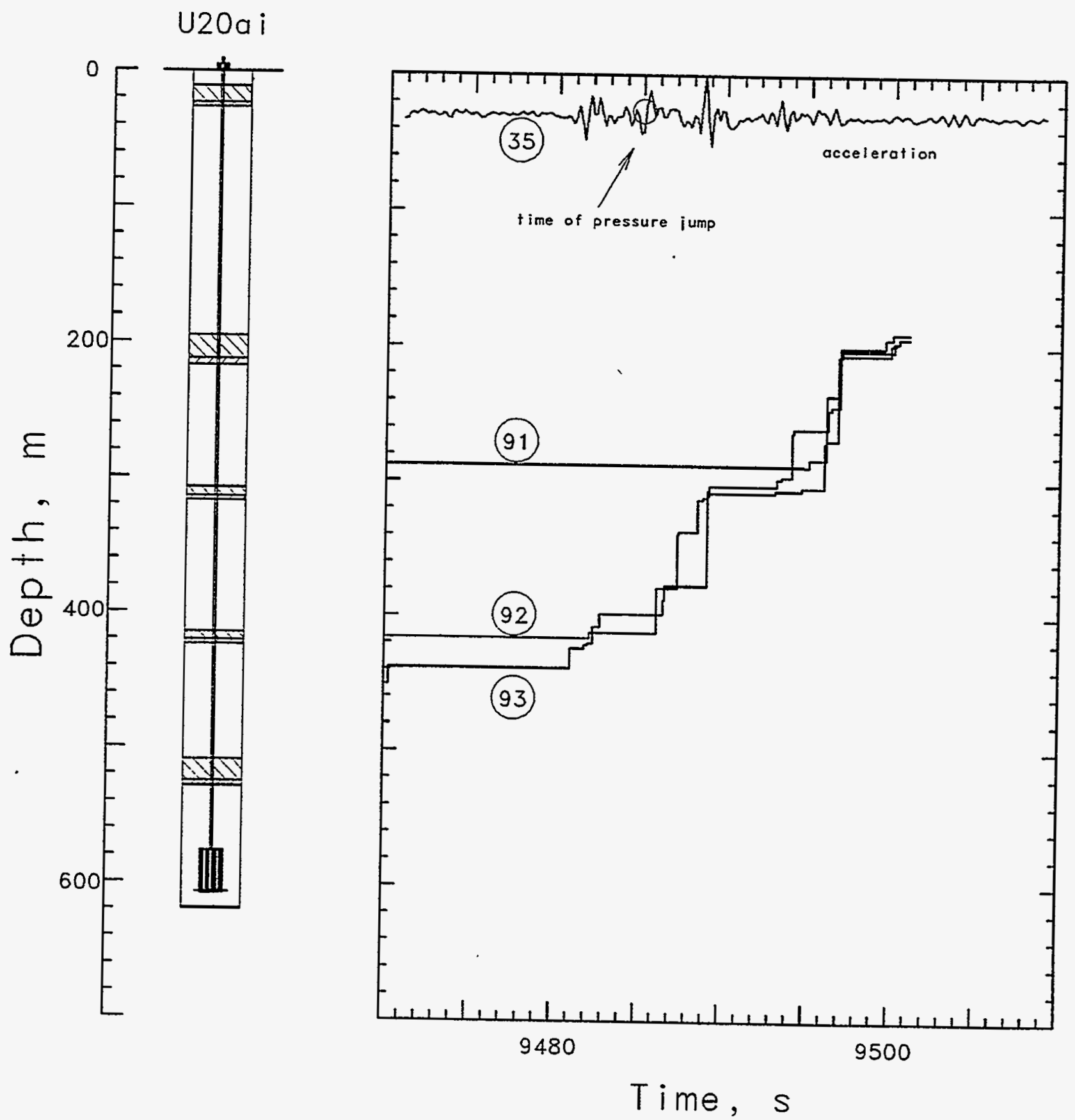

Figure 3.17 Collapse history as indicated by breaks in the EXCOR cables (stations 91, 92 and 93). The datum indicated by the circle indicates the time (9485 s) at which the pressure at station 35 increases by about $0.1 \mathrm{psi}$ (see figure 3.5). Also shown is the acceleration history from station 35 at the approximate depth of the station (see figure 3.18). 

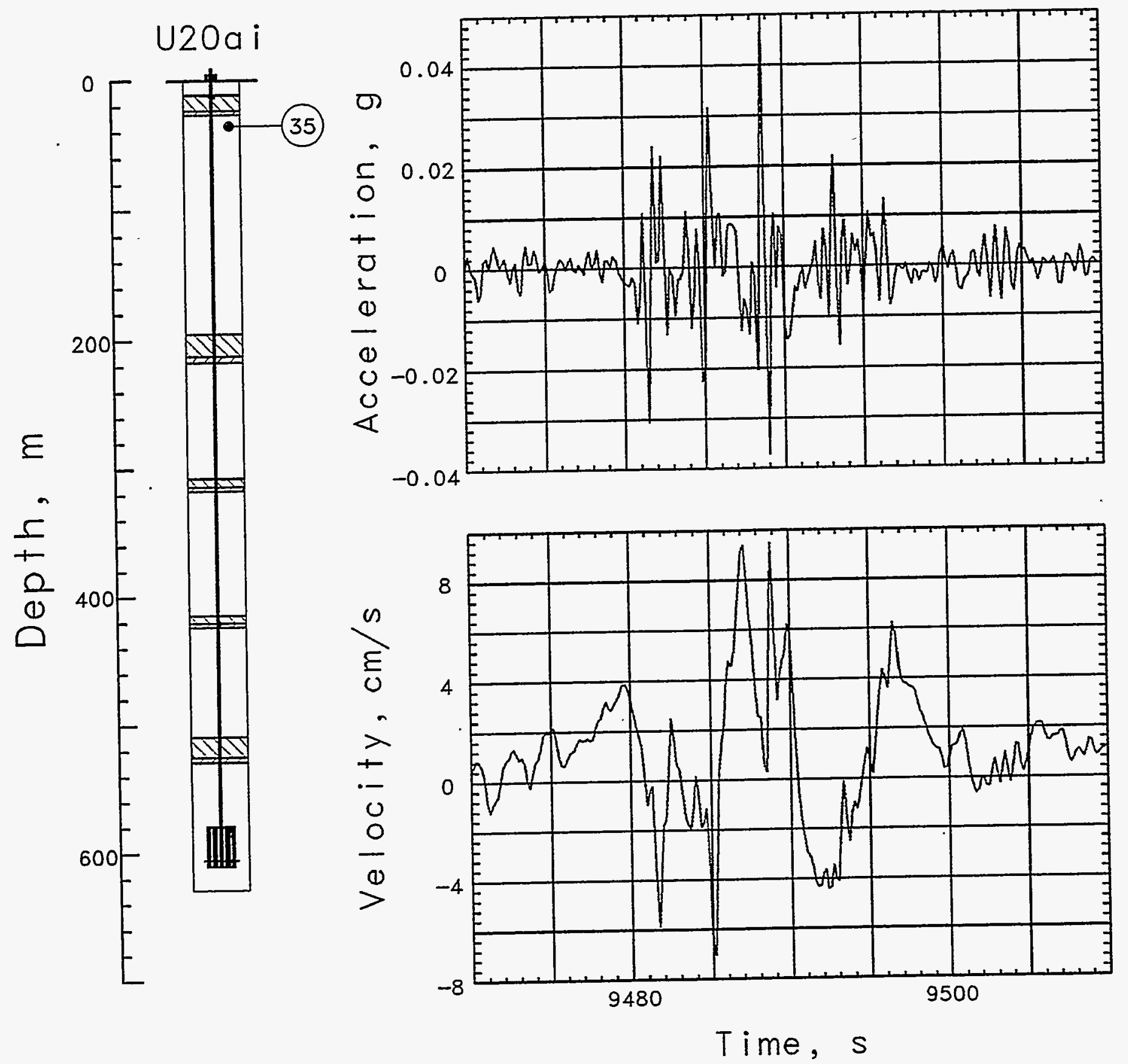

Figure 3.18 Collapse-induced vertical motion in the coarse stemming of the emplacement hole at a depth of $31.4 \mathrm{~m}$ (station 35 ). The acceleration is integrated once to velocity: the record is not of good enough quality to obtain meaningful displacement. 

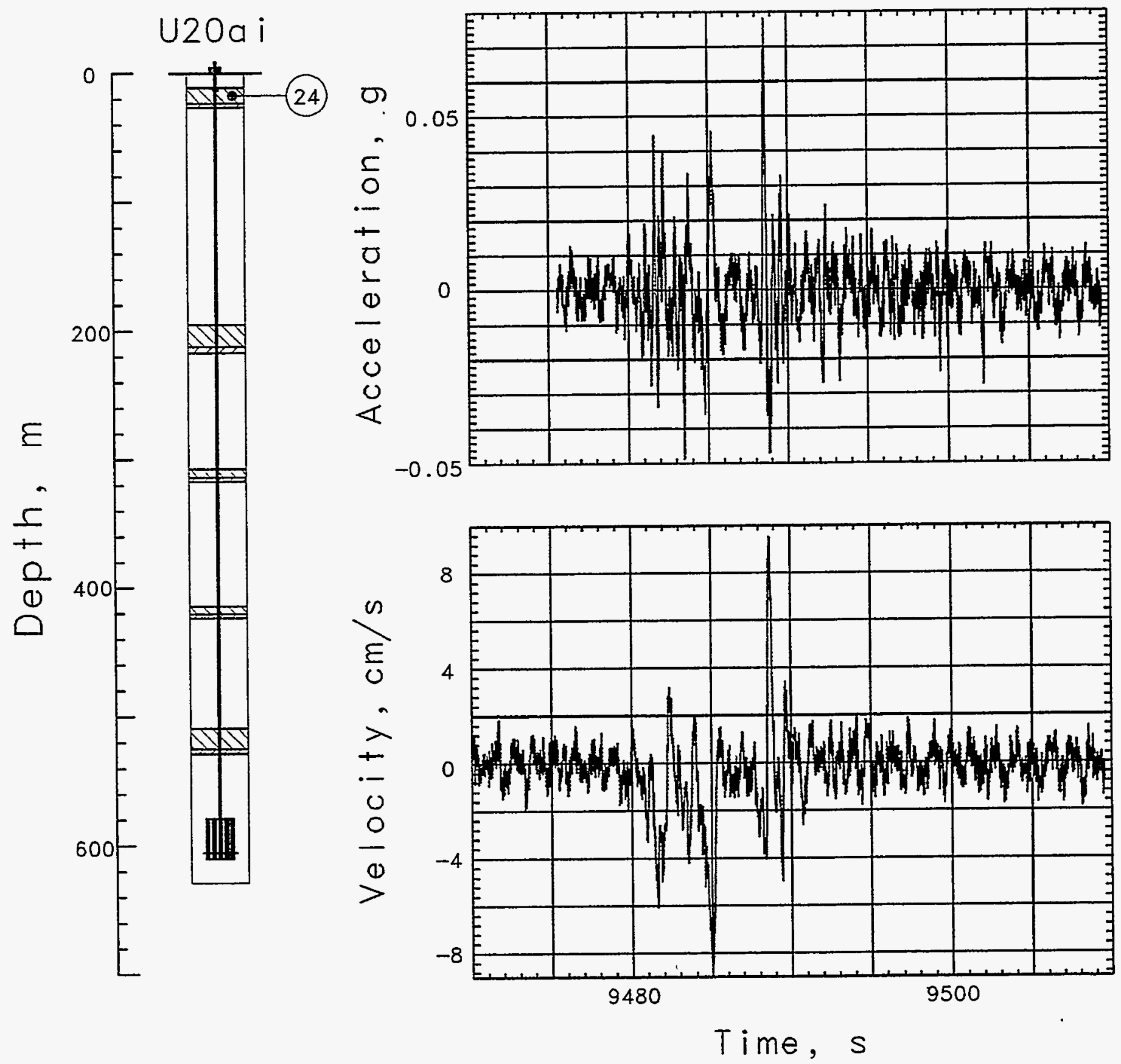

Figure 3.19 Collapse-induced vertical motion of the top plug at a depth of $17.7 \mathrm{~m}$ (station 24). Only the measured acceleration and velocity are presented. 

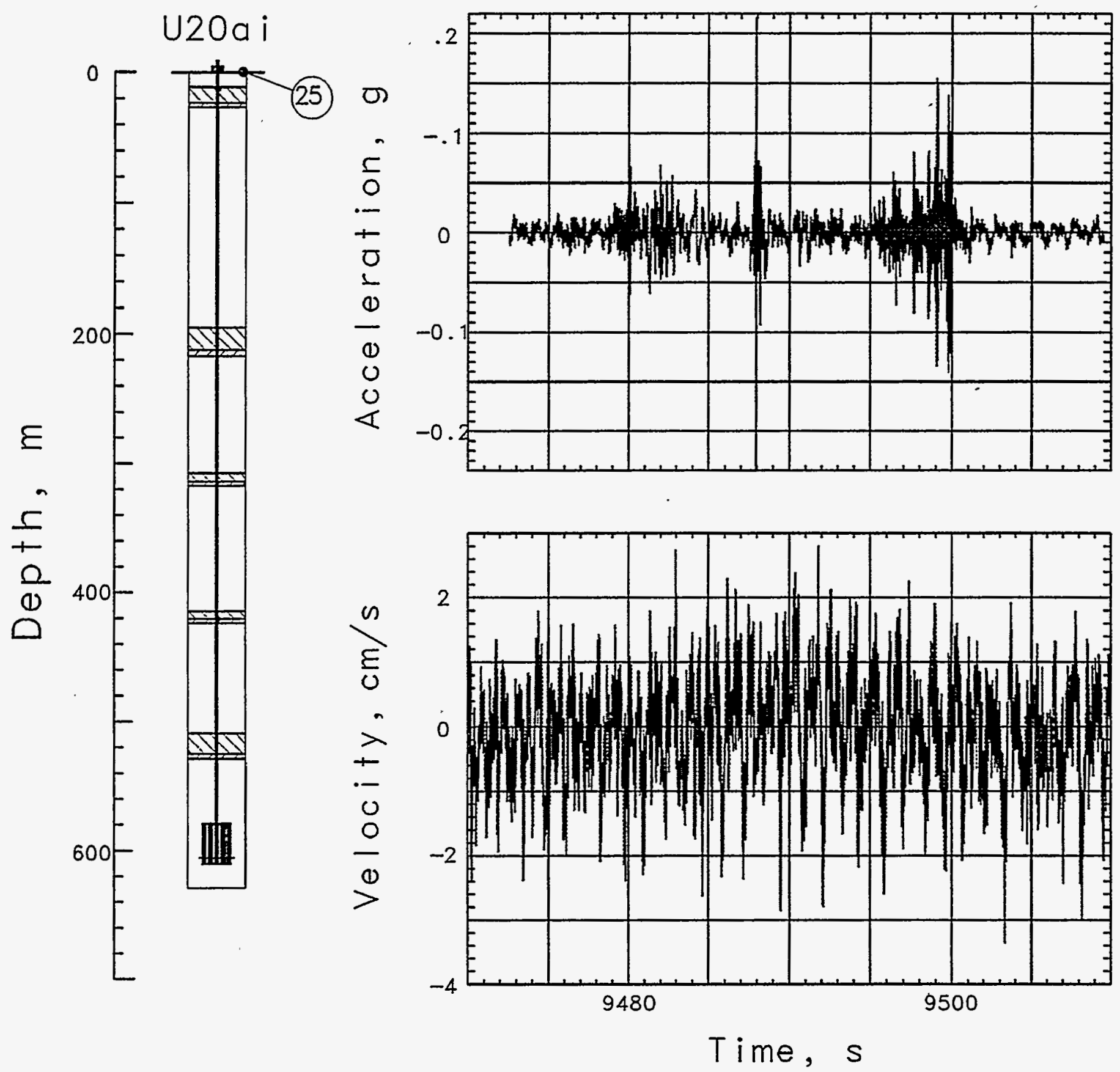

Figure 3.20 Collapse-induced vertical motion of the surface casing (station 25). Only the measured acceleration and velocity are presented. 

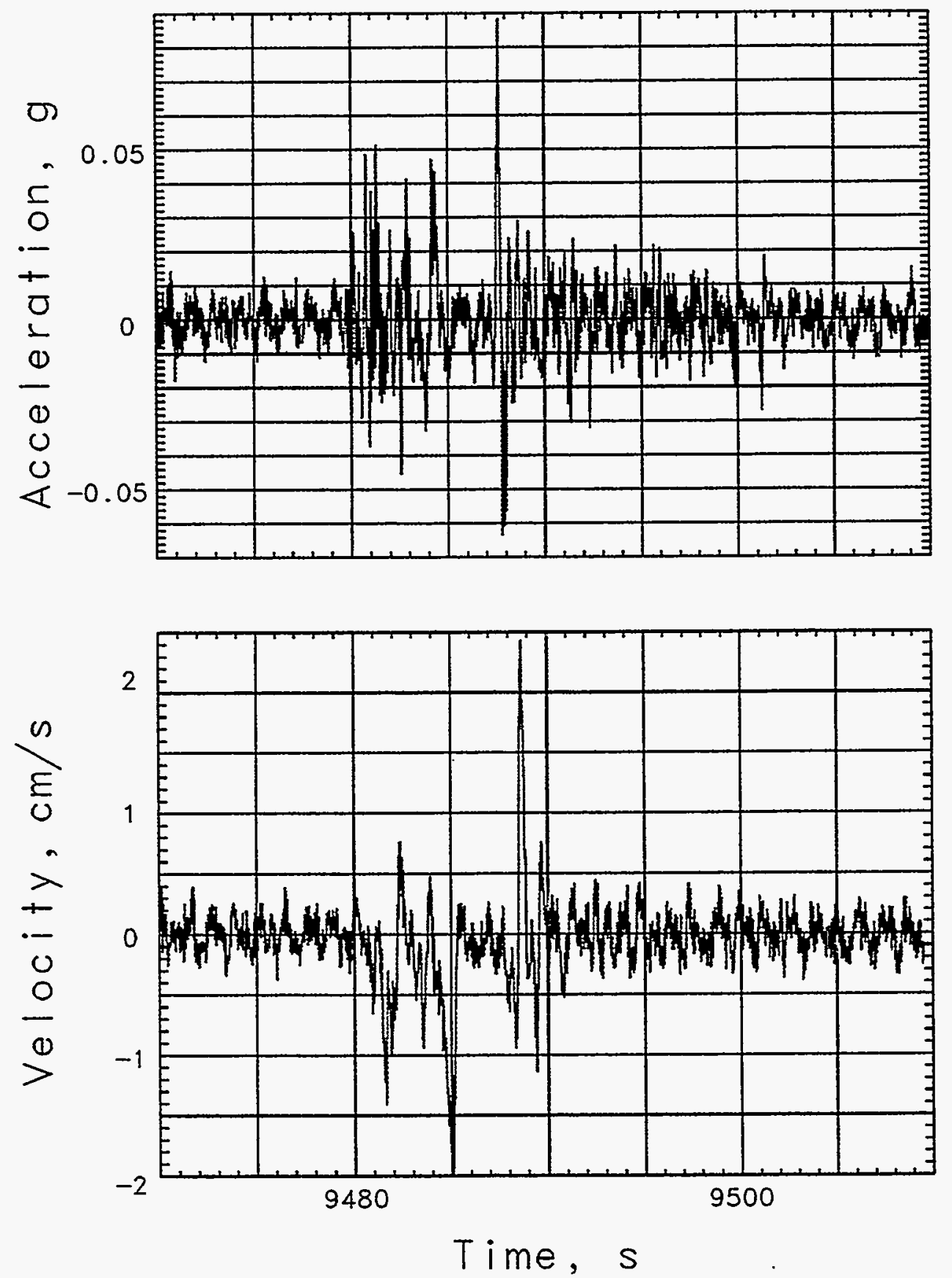

Figure 3.21 Collapse-induced vertical motion $0.91 \mathrm{~m}$ deep in the ground surface at a horizontal distance of $15.24 \mathrm{~m}$ from Surface Ground Zero (station 61 ). Only the measured acceleration and velocity are presented. 


\section{Other Measurements}

\subsection{Motion in the LLNL trailer park}

Figure 4.1 shows data as recorded on a high sensitivity accelerometer and a geophone mounted in the ground surface of the trailer park (station 62). Included is the entire recording period from a few minutes before detonation to a few minutes after subsurface subsidence. The low seismic activity from JEFFERSON is evident from these records.

Triaxial motion of the recording trailer is shown in figures 4.2-4.4. Motion sensed during the collapse episode at about $5740 \mathrm{~s}$ was of too low an amplitude for meaningful reduction and is not shown.

\subsection{Permeability data}

As part of a continuing investigation of the permeability of the upper geologic layers of the Nevada Test Site, sensitive pressure transducers were fielded in the emplacement hole beneath each of the two upper SGC plugs. One station was below the fifth plug and two were in the coarse stemming beneath the top plug and a fourth was placed $0.61 \mathrm{~m}$ deep in the ground surface $15.2 \mathrm{~m}$ from Surface Ground Zero. Data were digitally recorded from about 2 months prior to the event to event time and are shown in figure 4.5.

\subsection{Stress and strain}

Radial and transverse stress and strain were monitored at two locations in the bottom plug using transducers (developed by Dynasen, Inc. ${ }^{6}$ ) which, in principal, allow the removal of the strain contribution to the record of the stress transducer. Each location was monitored with transducer packages, each containing two elements (one being Ytterbium and the other constantan) having initial unstrained resistances of about $300 \Omega$. The elements were coupled to the stress field with a thin layer of fluid in an attempt to preclude inhomogenietes introduced by the required cladding on the package. Figures 4.5 and 4.6 show the fractional resistance change $(\% \Delta R / R)$ histories obtained from these instruments. Only three of the eight elements between these two stations survived the shock arrival (at about $48 \mathrm{~ms}$ ) with all signals being lost just after $100 \mathrm{~ms}$. The EMP introduced a large signal component on each of the channels, lasting at least until shock arrival. This casts doubt on the usefulness of the information from those elements that survived the shock. 
Table 4.1 Summary of Motion

\begin{tabular}{lcccccc} 
Gauge & $\begin{array}{c}\text { Slant Range } \\
(\mathrm{m})(\mathrm{a})\end{array}$ & $\begin{array}{c}\text { Arrival Time } \\
(\mathrm{ms})\end{array}$ & $\begin{array}{c}\text { Peak } \\
\text { Acceleration } \\
(\mathrm{g})\end{array}$ & $\begin{array}{c}\text { Peak } \\
\text { Velocity } \\
(\mathrm{m} / \mathrm{s})\end{array}$ & $\begin{array}{c}\text { Peak } \\
\text { Displacement } \\
(\mathrm{m})\end{array}$ & $\begin{array}{c}\text { Residual } \\
\text { Displacement } \\
(\mathrm{cm})\end{array}$ \\
\hline 71 av & $680(\mathrm{a})$ & 398 & $2.1,3.4^{(\mathrm{b})}$ & 1.6 & 0.60 & -15 \\
$71 \mathrm{uv}$ & & - & - & 2.4 & 0.48 & -15 \\
$71 \mathrm{ar}$ & $680(\mathrm{a})$ & 387 & 3 & 0.9 & 0.67 & $(\mathrm{c})$ \\
$71 \mathrm{ur}$ & & - & - & 1.4 & 1.13 & $(\mathrm{c})$ \\
71 at & $680(\mathrm{a})$ & 385 & 0.7 & $0.1,0.27$ & $0.06(\mathrm{c})$ & $(\mathrm{c})$ \\
$71 \mathrm{ut}$ & & - & - & $0.08,0.25$ & $0.033(\mathrm{c})$ & $(\mathrm{c})$
\end{tabular}

(a) Range is approximate: stations are in recording trailer .

(b) Slap-down peak.

(c) Signal lost before final value attained.

Table 4.2 Accelerometer Characteristics

\begin{tabular}{cccc} 
Gauge & $\begin{array}{c}\text { Natural Frequency } \\
(\mathrm{Hz})\end{array}$ & Damping Ratio & $\begin{array}{c}\text { System Range } \\
\left(g^{\prime} \mathrm{s}\right)\end{array}$ \\
\cline { 3 - 4 } 71av & 330 & 0.70 & 20 \\
71ar & 340 & 0.70 & 15 \\
71 at & 310 & 0.75 & 15
\end{tabular}

Table 4.3 Velocimeter Characteristics

\begin{tabular}{|c|c|c|c|c|c|}
\hline Gauge & $\begin{array}{c}\text { Natural } \\
\text { Frequency } \\
(\mathrm{Hz})\end{array}$ & $\begin{array}{l}\text { Time to } 0.5 \\
\text { Amplitude } \\
\text { (s) }\end{array}$ & $\begin{array}{c}\text { Calibration } \\
\text { Temperature } \\
\left({ }^{\circ} \mathrm{C}\right)\end{array}$ & $\begin{array}{c}\text { Operate } \\
\text { Temperature } \\
\left({ }^{\circ} \mathrm{C}\right)\end{array}$ & $\begin{array}{c}\text { System } \\
\text { Range } \\
(\mathrm{m} / \mathrm{s})\end{array}$ \\
\hline 71 uv & 3.253 & 12.03 & 24.42 & 18.75 & 7 \\
\hline 7iur & 3.516 & 9.59 & 24.74 & 18,75 & 5 \\
\hline 71 ut & 3.354 & 8.87 & 25.41 & 18.75 & 5 \\
\hline
\end{tabular}



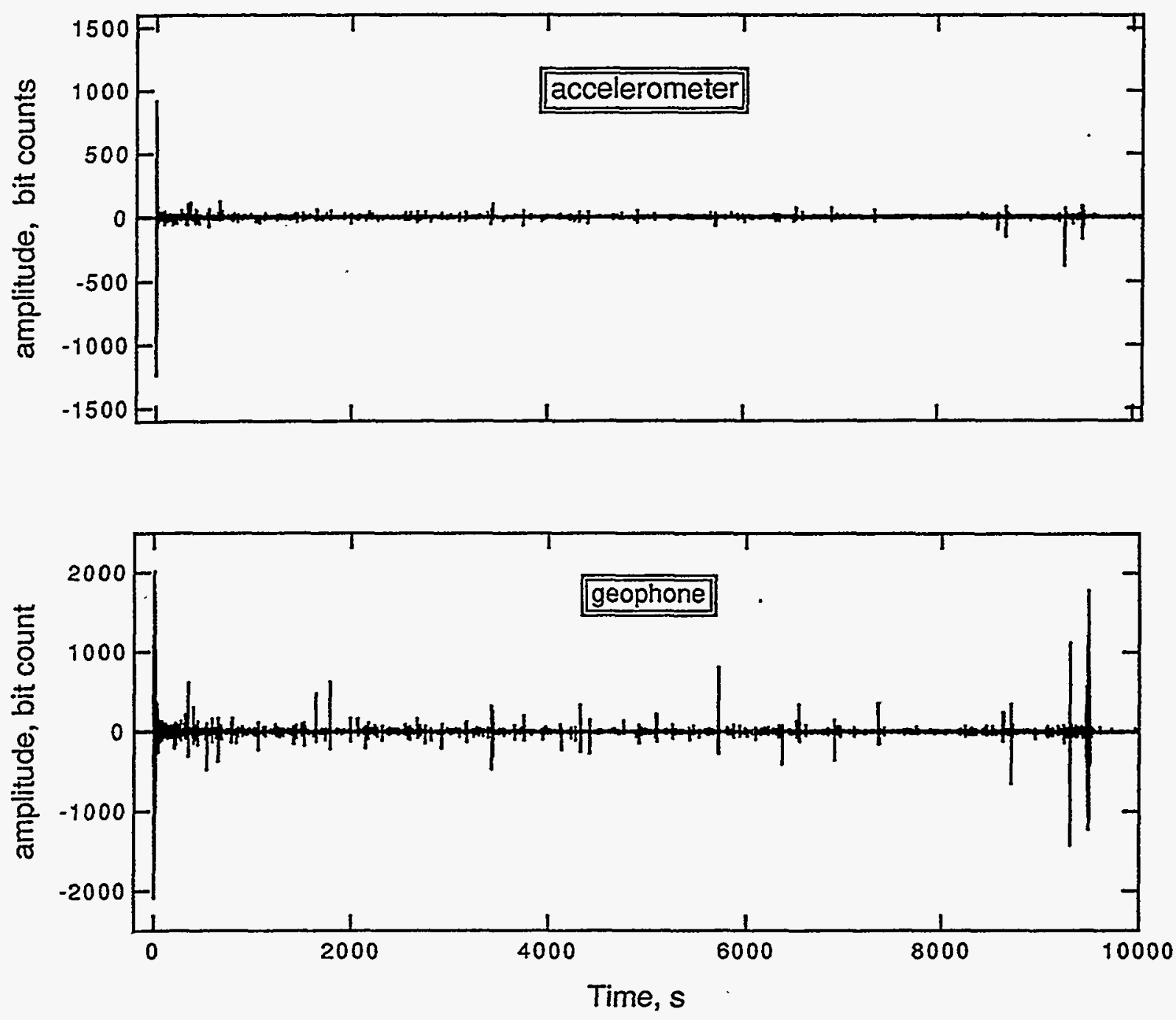

Figure 4.1 Data from the vertical geophone and sensitive accelerometer mounted in the ground surface at the recording trailer (station 62). Subsurface subsidence to a depth of about 190 m occurred at about $2 \mathrm{hr}, 37 \mathrm{~min}$. 

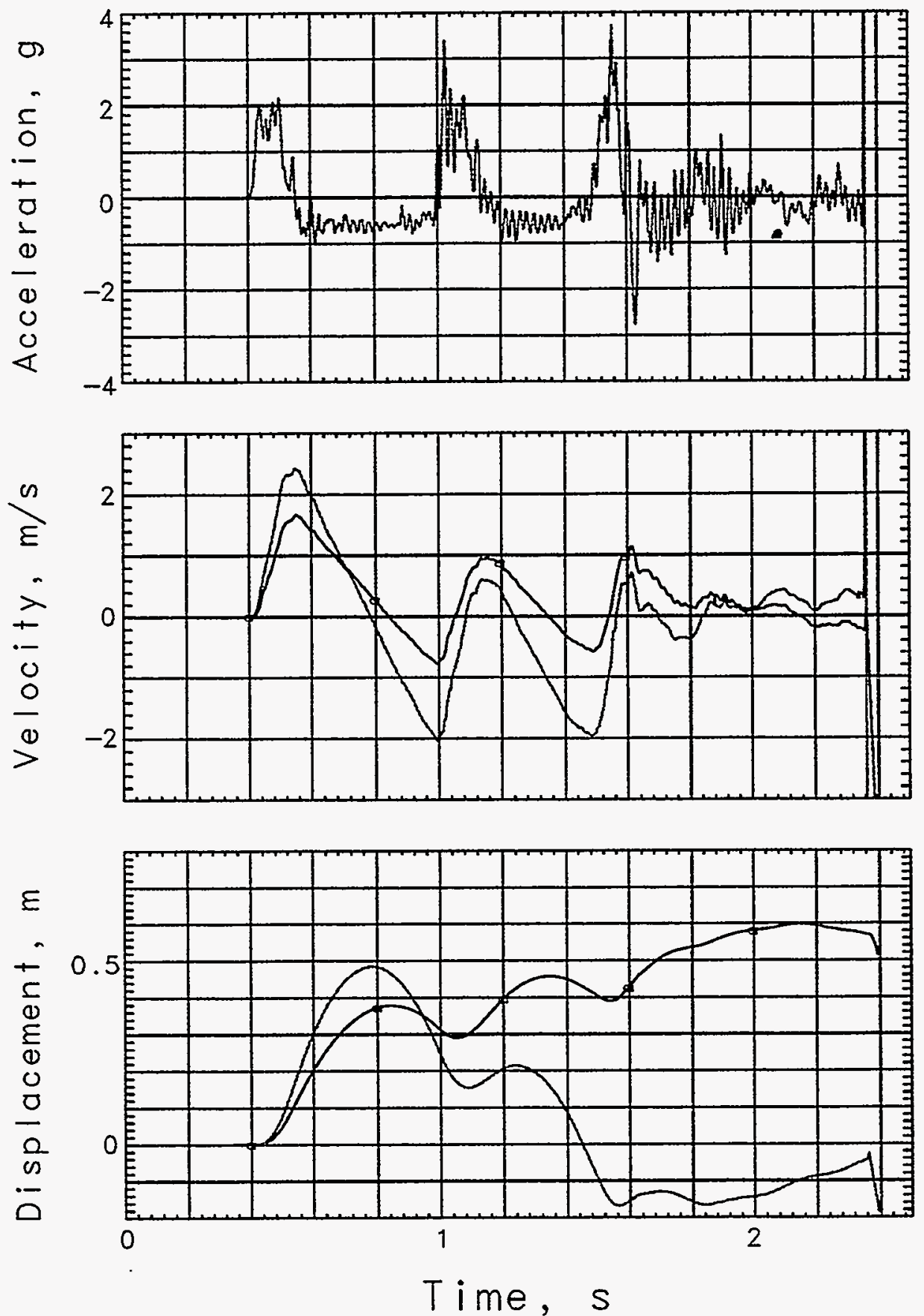

Figure 4.2 Explosion-induced vertical motion of the recording trailer (station 71). Data records annotated with an 'a' are derived from the accelerometer. Station signals were interrupted at about $2.4 \mathrm{~s}$ after detonation. 

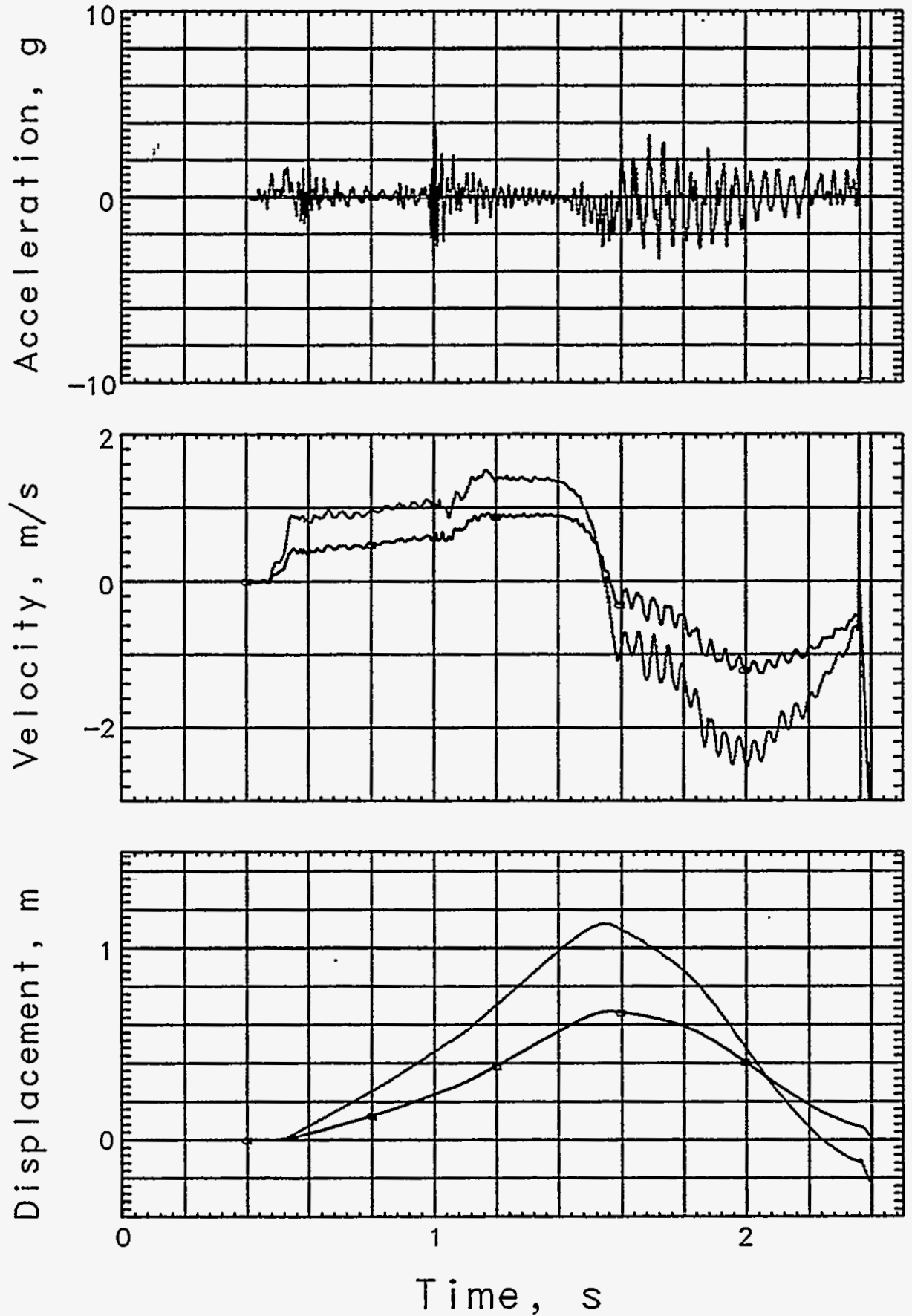

Figure 4.3 Explosion-induced horizontal-radial motion of the recording trailer (station 71). Data records annotated with an 'a' are derived from the accelerometer. Station signals were interrupted at about $2.4 \mathrm{~s}$ after detonation. 

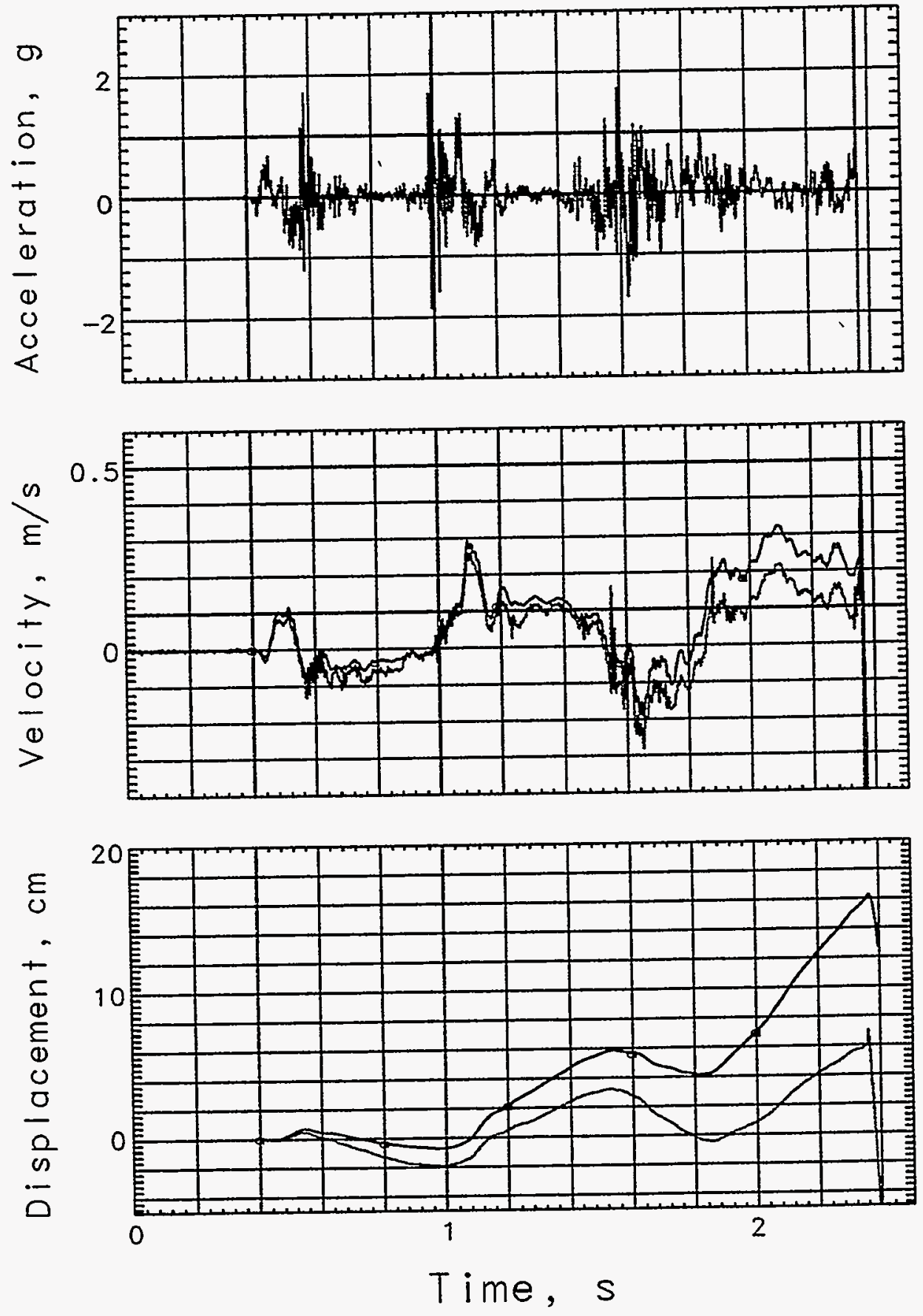

Figure 4.4 Explosion-induced horizontal-transverse motion of the recording trailer (station 71). Data records annotated with an ' $a$ ' are derived from the accelerometer. Station signals were interrupted at about $2.4 \mathrm{~s}$ after detonation. 

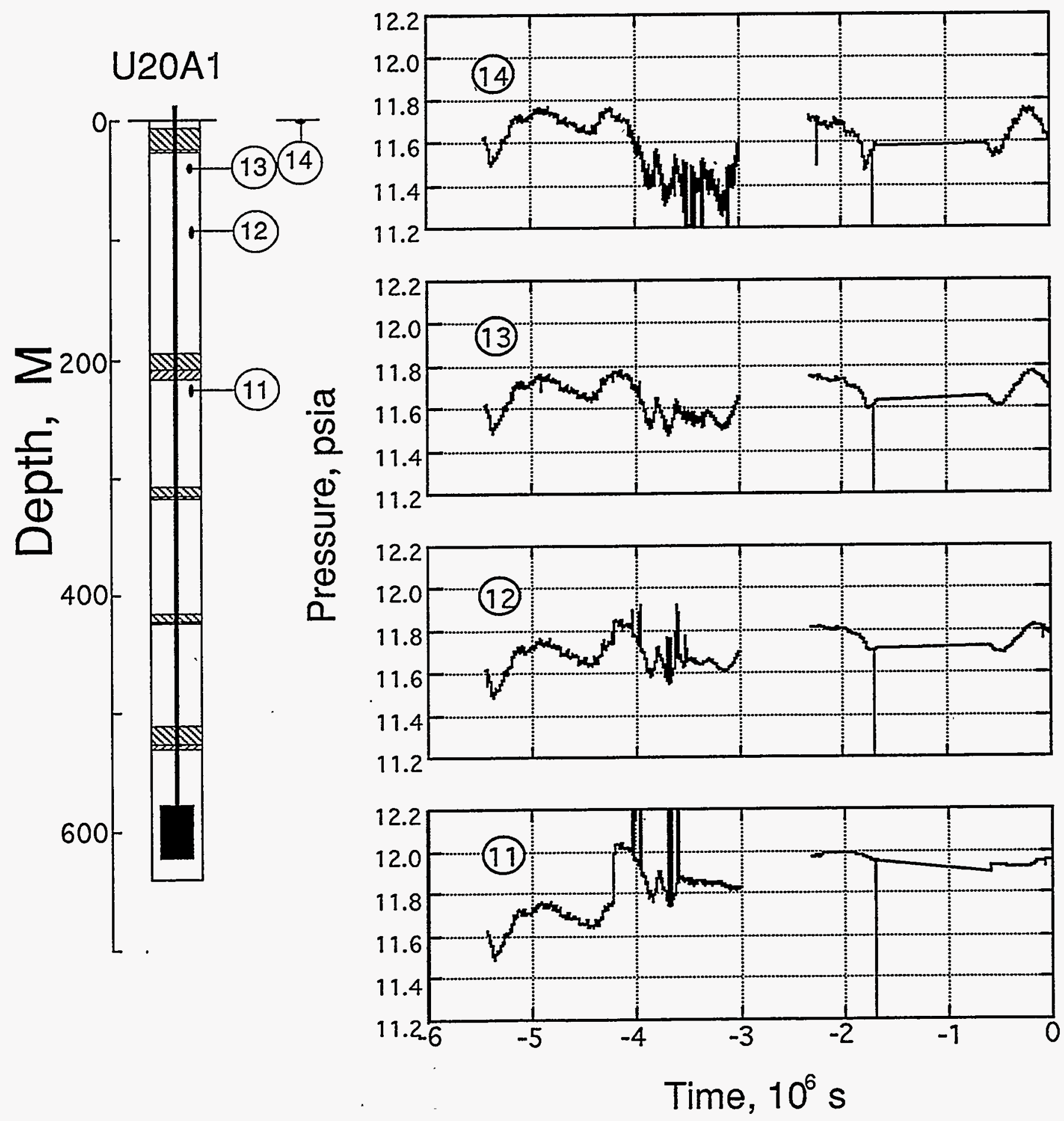

Figure 4.5 Permeability pressure data measured in hole U20ai prior to the event. Time is relative to the event. 


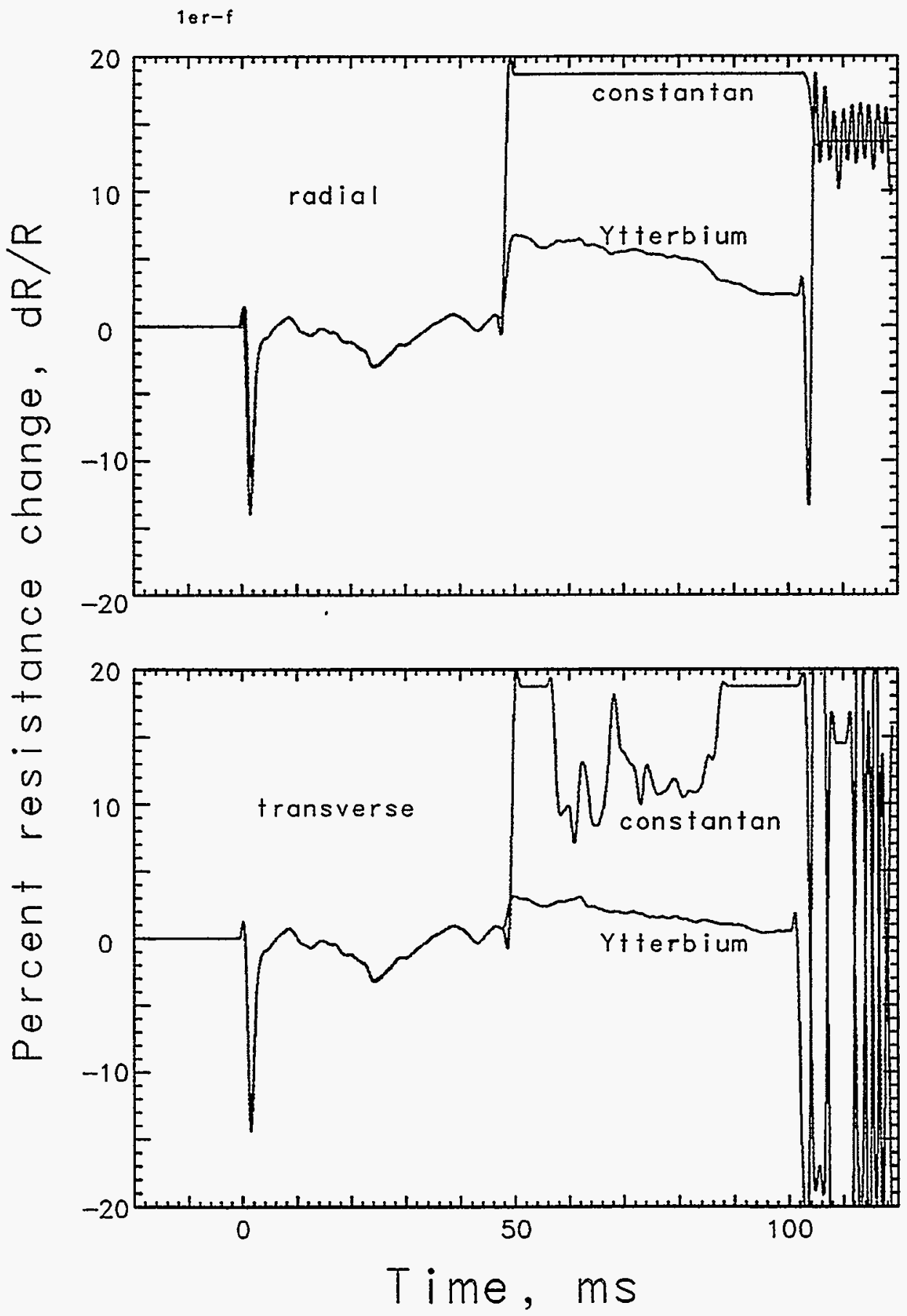

Figure 4.6 Output from the two element stress \& strain transducers mounted to sense radial and transverse information at.a range of $94.1 \mathrm{~m}$ from the working point (station 1). The signal prior to $48 \mathrm{~ms}$ is due to system excitation from the EMP. Both stress and strain signals are lost shortly after $0.1 \mathrm{~s}$ 


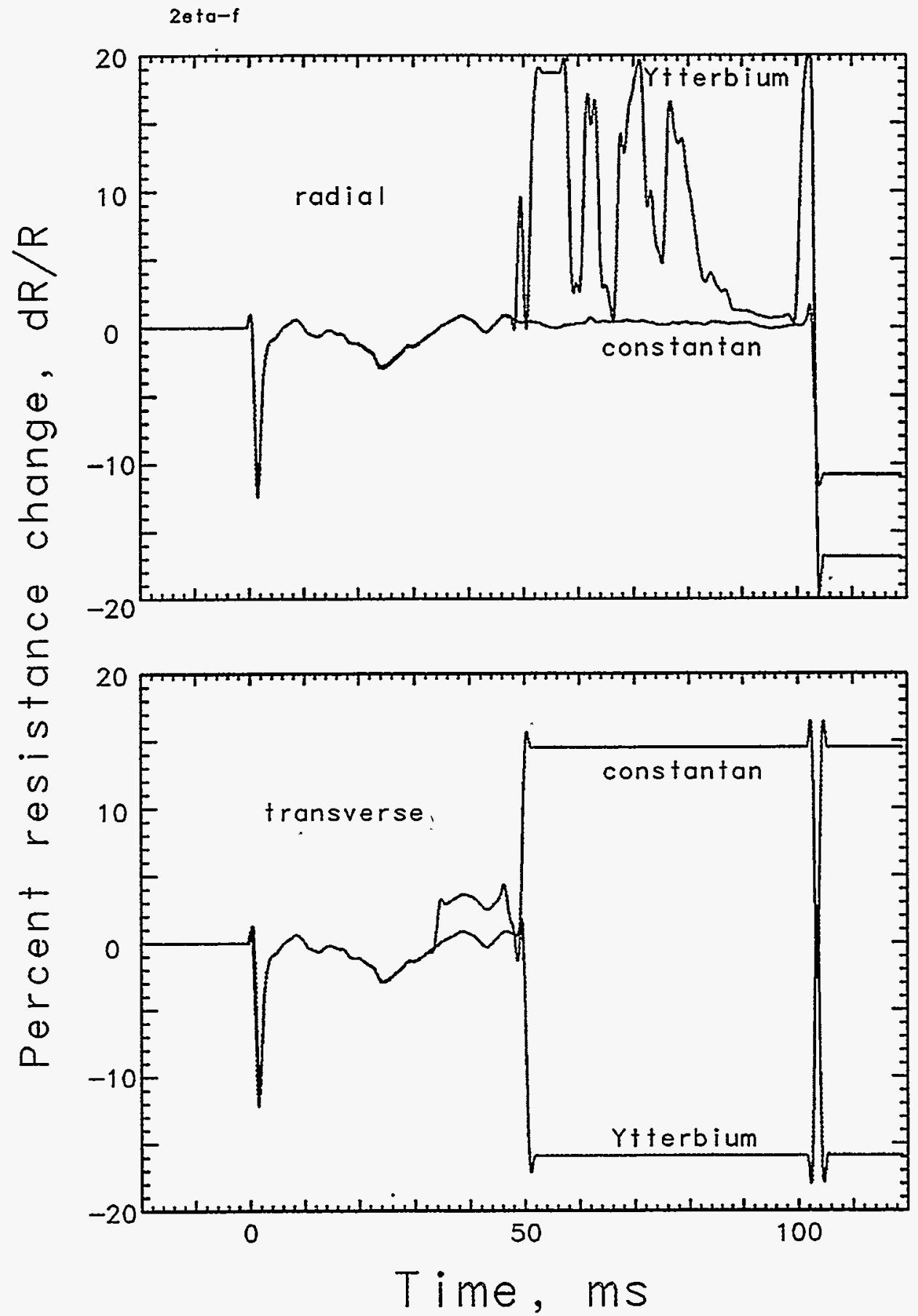

Figure 4.7 Output from the two element stress \& strain transducers mounted to sense radial and transverse information at a range of $95.6 \mathrm{~m}$ from the working point (station 2). The signal prior to $48 \mathrm{~ms}$ is due to system excitation from the EMP. Both stress and strain signals are lost shortly after $0.1 \mathrm{~s}$ 


\section{References}

1. J. L. Wagoner, "U20ai Site Characteristics Report", CP 85-86, Lawrence Livermore National Laboratory, Livermore, CA, October 14, 1985.

2. Alfred R. Burer, "Containment Report for U20ai", Holmes \& Narver, Inc., NTS:A2:86-23, March 31, 1986.

3. LLNL contact for additional information: R. Heinle (CORRTEX data).

4. J. Kalinowski, T. Stubbs, L. Davies, and B. Hudson, "Recent stress gage developments", Range Commanders Council, Telemetry Group, 4-6 July, 1985, Monterey, California.

5. Richard A. Spilsbury, "Special Measurements Final Engineering Report for JEFFERSON, U20ai," EG\&G, Energy Measurements, Las Vegas, NV, SM:86E-133-35, 13 May 1986.

6. Richard A. Spilsbury, "Special Measurements Physics/Instrumentation package for JEFFERSON, U20ai, Revision 'A'" EG\&G, Energy Measurements, Las Vegas, NV, SM:86E-133-36, 13 May, 1986.

7. J. A. Kalinowski, "JEFFERSON Stress Gage Report", EG\&G, Energy Measurements, Pleasanton, CA, JAK 92-12, April 14, 1992. 
Distribution:

LLNL

TID (11)

Test Program Library

Containment Vault

Burkhard, N.

Cooper, $W$.

Denny, $M$.

Dong, $R$.

Goldwire, $H$.

Heinle, R. (5)

Mara, G.

Moran, M.T.

Moss, W.

Olsen, C.

Patton, $\mathrm{H}$,

Pawloski, G.

Rambo, J.

Roland, $\mathrm{K}$.

Roth, B.

Valk, $T$.

Younker, L.

LANL

App, $F$.

Brunish, $W$.

Kunkle, $T$.

Trent, B.

\section{Sandia}

Chabai, A.

Smith, Carl W.
L-053

L-045

$L-221$

$L-221$

L-049

L-205

$L-140$

L-221

$L-221$

L-049

L-777

L-200

L-221

L-205.

L-221

L-200

L-221

L-049

L-154

L-203

F-659

F-659

F-665

F-664

MS-1159

MS-1159

\section{EG\&G/AVO}

Brown, $T$.

Gilmore, L.

A-5

Hatch, $M$.

Still, G.

Stubbs, T.

A-1

A-5

A-5

A-5

EG\&G/NVO

Bellow, B.

N 13-20

Davies, $L$.

N 13-20

Moeller, A.

N 13-20

Robinson, $R$.

N 13-20

Webb, W.

N $13-20$

DNA

Ristvet, B.

S-Cubed

Peterson, E.

Eastman Cherrington Environment

1640 Old Pecos Trail, Suite H

Santa Fe, NM 87504

Keller, C. 